University of New Haven

University of

New Haven

Digital Commons@ New Haven

Mechanical and Industrial Engineering Faculty

Publications

Mechanical and Industrial Engineering

12-15-2016

\title{
Energy-Climate-Manufacturing Nexus: New Insights from the Regional and Global Supply Chains of Manufacturing Industries
}

\author{
Murat Kucukvar \\ Istanbul Sehir University \\ Bunyamin Canseva \\ Istanbul Sehir University \\ Gokhan Egilmez \\ University of New Haven, gegilmez@newhaven.edu \\ Nuri C. Onat \\ Arizona State University \\ Hamidreza Samadi \\ Istanbul Sehir University
}

Follow this and additional works at: https:// digitalcommons.newhaven.edu/ mechanicalengineering-facpubs

Part of the Industrial Engineering Commons, and the Mechanical Engineering Commons

\section{Publisher Citation}

Kucukvar, M., Cansev, B., Egilmez, G., Onat, N. C., \& Samadi, H. (2016). Energy-climate-manufacturing nexus: New insights from the regional and global supply chains of manufacturing industries. Applied Energy Volume 184, 15 December 2016, Pages 889-904. doi:10.1016/j.apenergy.2016.03.068

\section{Comments}

This is the authors' accepted version of the article published in Applied Energy. The version of record may be accessed via Elsevier's web site at http://dx.doi.org/10.1016/j.apenergy.2016.03.068 . 


\title{
Energy-Climate-Manufacturing Nexus: New Insights from the Regional and Global Supply Chains of Manufacturing Industries
}

\author{
Murat Kucukvara, Bunyamin Cansev ${ }^{\mathrm{b}}$, Gokhan Egilmez ${ }^{\mathrm{e}}$, Nuri C. Onat ${ }^{\mathrm{d}}$, Hamidreza \\ Samadi $^{\mathrm{e}}$ \\ a Assistant Professor, Department of Industrial Engineering, Istanbul Sehir University, Istanbul, 34662, Turkey \\ ${ }^{b, e}$ Research Assistant, Department of Industrial Engineering, Istanbul Sehir University, Istanbul, 34662, Turkey \\ ${ }^{c}$ Assistant Professor, Department of Mechanical, Civil, and Environmental Engineering, University of New Haven, \\ West Haven, CT, United States (*Corr. Author Email: Gegilmez@newhaven.edu , Phone: +1 (203) 497-4196) \\ d Assistant Professor, Department of Industrial Engineering, Istanbul Sehir University, Istanbul, 34662, Turkey \\ ${ }^{\mathrm{e}}$ Research Assistant, Department of Industrial Engineering, Istanbul Sehir University, Istanbul, 34662, Turkey
}

\begin{abstract}
The main objectives of this research are to improve our understanding of energy-climate-manufacturing nexus within the context of regional and global manufacturing supply chains as well as show the significance of full coverage of entire supply chain tiers in order to prevent significant underestimations, which might lead to invalid policy conclusions. With this motivation, a multi-region input-output (MRIO) sustainability assessment model is developed by using the World Input-Output Database, which is a dynamic MRIO framework on the world's 40 largest economies covering 1440 economic sectors. The method presented in this study is the first environmentally-extended MRIO model that harmonizes energy and carbon footprint accounts for Turkish manufacturing sectors and a global tradelinked carbon and energy footprint analysis of Turkish manufacturing sectors is performed as a case study. The results were presented by distinguishing the contributions of five common supply chain phases such as upstream suppliers, onsite manufacturing, transportation, wholesale, and retail trade. The findings showed that onsite and upstream supply chains are found to have over $90 \%$ of total energy use and carbon footprint for all industrial sectors. Electricity, Gas and Water Supply sector was usually found to be as the main contributor to global climate change, and Coke, Refined Petroleum, and Nuclear Fuel sector is the main driver of energy use in upstream supply chains. Overall, the largest portion of total carbon emissions of Turkish manufacturing industries was found in Turkey's regional boundary that ranged between 40 to $60 \%$ of total carbon emissions. In 2009, China, United States, and Rest-of-the-World's contribution is found to be more than $50 \%$ of total energy use of Turkish manufacturing. The authors envision that a global MRIO framework can provide a vital guidance for policy makers to analyze the role of global manufacturing supply chains and prevent significant underestimations due to inclusion of limited number of tiers for sustainable supply chain management research.
\end{abstract}

Key words Energy-Climate-Manufacturing Nexus; Multi-Region Input-Output Analysis; World Input-Output Database; Global Supply Chains; Sustainable Manufacturing. 


\title{
Energy-Climate-Manufacturing Nexus: New Insights from the Regional and Global Supply Chains of Manufacturing Industries
}

Corresponding Author Email: GEgilmez@,NewHaven.Edu

\begin{abstract}
The main objectives of this research are to improve our understanding of energy-climate-manufacturing nexus within the context of regional and global manufacturing supply chains as well as show the significance of full coverage of entire supply chain tiers in order to prevent significant underestimations, which might lead to invalid policy conclusions. With this motivation, a multi region input-output (MRIO) sustainability assessment model is developed by using the World Input-Output Database, which is a dynamic MRIO framework on the world's 40 largest economies covering 1440 economic sectors. The method presented in this study is the first environmentally-extended MRIO model that harmonizes energy and carbon footprint accounts for Turkish manufacturing sectors and a global trade-linked carbon and energy footprint analysis of Turkish manufacturing sectors is performed as a case study. The results were presented by distinguishing the contributions of five common supply chain phases such as upstream suppliers, onsite manufacturing, transportation, wholesale, and retail trade. The findings showed that onsite and upstream supply chains are found to have over $90 \%$ of total energy use and carbon footprint for all industrial sectors. Electricity, Gas and Water Supply sector was usually found to be as the main contributor to global climate change, and Coke, Refined Petroleum, and Nuclear Fuel sector is the main driver of energy use in upstream supply chains. Overall, the largest portion of total carbon emissions of Turkish manufacturing industries was found in Turkey's regional boundary that ranged between 40 to $60 \%$ of total carbon emissions. In 2009, China, United States, and Rest-of-the-World's contribution is found to be more than $50 \%$ of total energy use of Turkish manufacturing. The authors envision that a global MRIO framework can provide a vital guidance for policy makers to analyze the role of global manufacturing supply chains and prevent significant underestimations due to inclusion of limited number of tiers for sustainable supply chain management research.
\end{abstract}

Key words Energy-Climate-Manufacturing Nexus; Multi-Region Input-Output Analysis; World Input-Output Database; Global Supply Chains; Sustainable Manufacturing. 


\section{Introduction}

According to the World Energy Outlook Energy Special Report published by the International Energy Agency, the world is unfortunately not on the track to achieve the global climate change targets set by the world leaders and we are running out of time to mitigate the rise of global temperature to 2 degrees Celsius (IEA, 2013). While we have already fallen far behind the sustainable development goals that we have to reach for our common future, the human beings have found themselves in the midst of the environmental, economic, social and political problems fueled by lack of an energy security and steeply rising carbon emissions. European economy has also become an energy and resource dependent economy and vulnerable to rising energy prices and raw material supply shocks (European Commission, 2013). These facts inevitably lead the policy makers to take solid actions toward a greener and resource efficient economy, and therefore the European manufacturing industry has been identified as one of the most important policy areas that need urgent attention.

Statistics indicate that, European manufacturing represented approximately $26.8 \%$ of the European Union (EU)'s GDP and $22.6 \%$ of its employment, providing more than 30 million jobs (European Commission, 2013). While manufacturing activities contribute significantly to the European economies and create critical socio economic benefits to the societies, their shares in the overall energy consumption and global climate change impacts are also considerably high compared to other industries due to the resource and energy intensity embed in the processes. Recent reports indicated that manufacturing sectors responsible for substantial amount of greenhouse gas (GHG) emissions in the Europe, which are the third largest contributors after the power generation and transportation sectors (European Environment Agency, 2013). In addition, European manufacturing is responsible for around $25 \%$ of total energy consumption, which is the third biggest energy consumer industry after the transportation sector and household consumption (European Commission, 2013).

Sustainable manufacturing has inevitably become an integral part of EU's sustainable development plans to support the EU's 2020 strategic plan on promoting sustainable industrial growth through low-carbon and energyefficient production and economy (European Commission, 2014). To realize these goals, the European Union developed an integrated policy strategy for climate and energy policies which aims to combat with global climate change and improve the EU's energy security, simultaneously (Helm, 2014). Such an integrated approach is necessary since energy consumption and climate change are fundamentally connected issues and it is not practical to look at these environmental challenges in isolation (WBCSD, 2009). In this regard, EU's 2020 strategies on analyzing 'energy-climate nexus' are covered under the '20-20-20' targets and identified as accomplishing a 20\% reduction in GHG emissions from 1990 levels, raising the share of renewable energy resources to 20\%, and having a $20 \%$ improvement in the EU's energy efficiency (European Commission, 2014). In parallel with the EU's '2020-20' targets, the Turkish Ministry of Environment and Urban Planning has recently made the carbon footprint reporting mandatory for industrial facilities and started to develop pilot projects on carbon emissions of selected industrial sectors. Based on the information released in the Ministry's official website, manufacturing sectors in Turkey must annually measure, report and validate their carbon emissions starting from 2015 (Turkish Ministry of Environment and Urban Planning, 2014). Furthermore, the Turkish Ministry of Energy and Natural Resources developed an energy strategy plan in which a $20 \%$ primary energy intensity reduction is targeted for 2023 compared with the 2008 level (Turkish Ministry of Energy and Natural Resources, 2013).

To realize sustainable development goals based on the aforementioned climate and energy strategies, sustainability impacts of European and Turkish manufacturing have to be analyzed from a supply chain 
perspective. The supply chain encompasses all activities associated with the flow of goods and information from raw material extraction and processing through the customer (Seuring and Müller, 2008). The concept of sustainability in the supply chain management has become a topic of considerable interest worldwide and highly discussed in the regional policy making (Ahi and Searcy, 2013; Ayvaz et al. 2015; Park et al. 2015; Park et al. 2016; Sarkis et al., 2011; Seuring, 2013; Soysal et al. 2014). Especially, system thinking in sustainable supply chain management is very crucial due to the fact that environmental impacts are variably located in the first, second, third, and even higher tiers of the supply chains of the manufacturing sectors. The results of past studies also indicated that focusing solely on the onsite or limited tiers of upstream supply chain impacts could result in significant underestimation about the overall impacts, which might lead to invalid policy outcomes (Egilmez et al. 2013; Egilmez et al. 2014; Feng et al. 2011).

In the literature, process-based life-cycle assessment (LCA), economic input-output based LCA, and hybrid LCA are extensively used to quantify the environmental impacts of products or processes (Bush et al. 2014; Onat et al. 2015a, b; Suh et al. 2004). In fact, when focusing on the holistic environmental burdens of large-scaled systems such as industrial sectors, Input-Output (I-O) based sustainability assessment models are more comprehensive approaches, which provide a macro-level analysis (Chen and Chen, 2015; Liu et al. 2012; Onat et al. 2014a; Song et al. 2015). The necessity of using system-based I-O models arises from the fact that process-based models involve the limited number of processes and inclusion or exclusion of processes is decided on the basis of subjective choices, which create the so-called system boundary problem (Onat et al. 2016a; Suh et al., 2004). Earlier studies on the carbon and energy footprints of economic sectors showed that process-based life-cycle inventories suffer from significant truncation errors which can be order of 50\% or higher (Feng et al. 2011; Kucukvar and Tatari 2013; Lenzen, 2000; Matthews et al. 2008). At this point, I-O based models provide a topdown analysis that uses sectoral monetary transaction matrixes considering complex interactions between the sectors of national economies (Li et al. 2012; Onat et al. 2014b; Wiedmann and Minx, 2008). I-O analysis is widely used and accepted as a suitable methodological approach for calculation of energy and carbon footprints (Kucukvar et al. 2014; Larsen and Hertwich, 2010; Lin et al. 2013; Minx et al. 2009; Wiedmann, 2009). Although, the majority of studies using I-O analysis were case studies that focus on carbon or energy footprint analysis of a single country for a single year (Hoekstra, 2010), a Multi Region Input-Output (MRIO) analysis is critical in order to take into account the role of international trade over a period of time (Arto et al. 2015; Peters and Hertwich, 2009; Wiedmann and Barret, 2013). This is important since the majority of countries in the world prefer open economic structure, which allows the importing goods and services from foreign countries. Hence, single-region models could lead to erroneous results due to unrealistic domestic technology assumption (Tukker and Dietzenbacher, 2013; Dietzenbacher et al. 2013).

In this regard, MRIO models have extensively used in carbon and energy footprint studies (Ewing et al. 2012; Lan et al. 2016; Liang et al. 2007; Mundaca et al. 2015; Zhang et al. 2014). Currently, there are a number of global MRIO models available in the literature and/or online. These databases are named as EoRA, Externality Data and Input-Output Tools for Policy Analysis (EXIOPOL), Global Trade Analysis Project (GTAP), and World InputOutput Database (WIOD) (Andrew and Peters 2013; Lenzen et al. 2013; Moran and Wood, 2014; Oita et al. 2016; Peters et al. 2011; Tukker et al. 2009). Several studies based the methodological framework on the aforementioned MRIO initiatives and focused on tracing the carbon and energy footprints of households (Galli et al. 2013; Weber and Matthews, 2008), consumption and production (Kucukvar et al. 2015; Kucukvar and Samadi, 2015; Yu et al. 2010; Yu et al. 2016; Zhang et al. 2014), international trade (Peters et al. 2011; Su and Ang, 2014; Wiedmann, 
2009), cities (Wiedmann et al. 2015), and nations (Andrew et al. 2009; Hertwich and Peters, 2009; Wiedmann et al. 2010).

\subsection{State-of-the-Art and Research Objectives}

Although there are solid actions taken to realize a low-carbon economy and energy-efficient manufacturing simultaneously, many policy questions still remain unanswered regarding the use of methodological approaches that can better estimate the carbon emissions and energy use of Turkish manufacturing sectors and identify significant energy and carbon hotspots for effective policy making. In addition, majority of research efforts focuses on particular parts of the manufacturing activates from products or processes with limited focus on regional impacts and supply chain phases. Although such efforts are necessary and useful, they lack of system perspective and therefore, underestimate the impacts from upper tiers of global supply chains. Based on the aforementioned research needs, this research aims to advance the body of knowledge by filling three major research gaps: "lack of application of MRIO methodology for global supply chain of national economies" and "lack of understanding of carbon-energy-manufacturing nexus", and "lack of holistic system-based decisionsupport methods for effective policy making”. In this regards, this research aims to provide answers the following questions:

* What are the direct and indirect carbon and energy footprint of Turkish manufacturing sectors at national and global level?

* What are the contributions of individual supply chain phases such as upstream suppliers, onsite manufacturing, transportation, wholesale and retail trade to overall carbon and energy footprint?

* What is the global distribution of upstream energy use and carbon footprints over a period of time?

* What is the nexus between energy and carbon footprints of each manufacturing sector based on major supply chain phases?

- What is the trend for national and global energy and carbon footprints of industrial sectors?

To be able to respond to the aforementioned policy questions adequately, a system-based holistic carbon and energy footprint accounting framework, which can capture all direct and indirect impacts at regional and global scale over a period of time, is required. Hence, in this paper, a global MRIO model is developed by utilizing the WIOD on the world's 40 largest economies covering 1440 economic sectors. By answering these questions, this paper will help the policy makers to

(i) identify the key industrial sectors and supply chain phases (upstream, onsite, transportation, wholesale and retail trade) with the greatest carbon and energy footprints for the period between 2000 and 2009,

(ii) determine the energy-climate nexus based on each supply chain phase,

(iii) propose effective carbon and energy footprint reduction strategies considering the regional and global supply chains of Turkish manufacturing sectors, and

(iv) show the importance of complete coverage of all supply chain tiers in order to prevent the erroneous results due to narrowly defined system boundary.

The rest of the paper is organized as follows. Section 2 introduces the methods. Results are provided in section 3. Discussion and conclusions were made in section 4, And, section 5 provides the policy recommendations and future directions of the current research. 


\section{Methods}

The MRIO models consist of trade flow matrices covering all countries or regions in the model. These matrices are able to track international supply chains of world economies and the global trade links among the trading partners (Arto et al. 2014a; Miller and Blair, 2009; Rueda-Cantuche et al. 2009). A MRIO model typically involves national input output (I-O) tables, which represent financial transactions between economic sectors within a country and international trade flows. In a typical MRIO framework, monetary flows present the amount of imports and exports made by economic sectors of countries. All these import and export flows are then merged into one consistent financial accounting framework (Tukker and Dietzenbacher, 2013). This combined interindustry transaction matrix is linked to primary inputs between economic sectors and final demand categories including household consumption, private fixed investments, and government purchases and investments (Wiedmann et al. 2011; Zhang et al. 2015).

In this research, the researchers used the WIOD to obtain monetary flows between the world's major economies represented by 40 countries. This database is supported by the European Commission under the 7th framework programme and developed a time series of symetric I-O tables during the period from 1995 to 2011 for 40 countries (27 EU member states and 13 other major countries, see Table 1) distinguishing 35 industries and 59 products (Dietzenbacher et al. 2013). In this database, an I-O table is constructed by using Supply and Use Tables at basic prices with a fixed product sales assumption. In this assumption, each product has its own specific sales structure irrespective of the industry where it is produced. All tables presented in the WIOD are obtained from the National Accounts Statistics (NAS) and are based primarily on publicly available data. For a detailed information about the sources and methods used in compiling the WIOD, constructing a symetric industry-by-industry I-O tables and detailed sector classifications, please refer to Timmer (2012) and EuroStat (2008).

Table 1. WIOD manufacturing sectors and their abbreviations

\begin{tabular}{lc}
\hline Manufacturing Sectors & Abbreviations \\
\hline Agriculture, Hunting, Forestry and Fishing & AHFF \\
Basic Metals and Fabricated Metal & BMFM \\
Chemicals and Chemical Products & CCP \\
Coke, Refined Petroleum and Nuclear Fuel & CRPNF \\
Electrical and Optical Equipment & EOE \\
Food, Beverages and Tobacco & FBT \\
Leather, Leather and Footwear & LLF \\
Machinery, Nec & MN \\
Manufacturing, Nec; Recycling & MNR \\
Mining and Quarrying & MQ \\
Other Non-Metallic Mineral & ONMM \\
Pulp, Paper, Paper, Printing and Publishing & PPPPP \\
Rubber and Plastics & RP \\
Textiles and Textile Products & TTP \\
Transport Equipment & TE \\
Wood and Products of Wood and Cork & WPWC \\
\hline
\end{tabular}

In our MRIO model, $\mathbf{A}^{r s} i j$ matrix consists of multiple rows which present the input of sector $i$ from country $r(=$ $1, \ldots, \mathrm{n})$ into industry $j$ in country $s(=1, \ldots, \mathrm{n})$. In this matrix, $i$ and $j$ equal to 35 which is the total number of sectors in each country. Also, $r$ and $s$ are equal to 41 which is the total number of countries including the Rest-of-theWorld (RoW). This matrix is also known as the direct requirement matrix, and each row represents the inputs from other sectors (domestic inputs plus inputs from other countries) to produce a dollar of output. Overall, the 
MRIO analysis produces a set of multipliers that show the total environmental impacts based on per dollar economic output, and therefore quantifies a global multiregional environmental footprint of supply chains (Wiedmann, 2009). After the MRIO model is constructed and total requirement matrix is derived from the direct requirement matrix using the taylor series approximation (Miller and Blair, 2009), carbon and energy footprints of the Turkish manufacturing sectors (presented in Table 2) can be estimated by multiplying the output of each sector by its carbon or energy impact per million dollar $(\$ \mathrm{M})$ of economic output. The mathematical foundation of a multi region input-output analysis is explained in the following sub-section.

Table 2. WIOD countries and their regional aggregation (Dietzenbacher et al. 2013)

\begin{tabular}{cccccc}
\hline Euro-Zone & Non-Euro EU & NAFTA & China & East Asia & BRIIAT \\
\hline Austria & Bulgaria & Canada & China & Japan & Brazil \\
Belgium & Czech Rep. & Mexico & & Korea & Russia \\
Cyprus & Denmark & USA & & Taiwan & India \\
Estonia & Hungary & & & & Indonesia \\
Finland & Latvia & & & & Australia \\
France & Lithuania & & & & Turkey \\
Germany & Poland & & & & \\
Greece & Romania & & & \\
Ireland & Sweden & & & \\
Italy & UK & & & & \\
Luxembourg & & & & \\
Malta & & & & \\
Netherlands & & & & \\
Portugal & & & & \\
Slovakia & & & & \\
Slovenia & & & & \\
Spain & & & & & \\
\hline
\end{tabular}

\subsection{A Multi-region Input-Output Analsis}

For a brief explaination, the MRIO model is illustrated for the case of 3 regions with $n$ sectors. However, this illustration can be applied to any number of regions and sectors as discussed in the Arto et al. (2014b). In a typical MRIO economy, there are 3 main components such as inter-industry transactions matrix $(\mathbf{Z})$, final demand vector (f), and total industry output vector (x).

$$
\begin{gathered}
Z=\left[\begin{array}{lll}
Z^{r r} & Z^{r s} & Z^{r t} \\
Z^{s r} & Z^{s s} & Z^{s t} \\
Z^{t r} & Z^{t s} & Z^{t t}
\end{array}\right] \\
\mathbf{f}=\left[\begin{array}{l}
f^{r} \\
f^{s} \\
f^{t}
\end{array}\right]=\left[\begin{array}{l}
f^{r r}+f^{r s}+f^{r t} \\
f^{s r}+f^{s s}+f^{s t} \\
f^{t r}+f^{t s}+f^{t t}
\end{array}\right] \\
x=\left[\begin{array}{c}
x^{r} \\
x^{s} \\
x^{t}
\end{array}\right]
\end{gathered}
$$

As an element of $\mathbf{Z}^{r s}, z_{i j}^{r s}$ accounts for the purchases of industry $j$ in country $s$ from industry $i$ in country $r$. In addition, $\mathbf{f}^{r s}$ represents a column vector with final demands that can be household demand, government consumption and investments, private fixed investments, etc. For example, $f_{i}^{r s}$ represents the final demand of country s for commodities produced by sector $i$ in country $r$. Also, $\mathbf{x}^{r}$ denotes the column vector of total industry outputs in region $r$. Overall, the linear relation between total industry output $(\mathbf{x})$, inter-industry transactions $(\mathbf{Z})$ and final demand (f) is given in eqn.1 (Miller and Blair, 2009): 


$$
\mathbf{Z i}+\mathbf{f}=\mathbf{x}
$$

where i represents the vector of column summation.

In a standard input-output model, total industry output vector, $\mathbf{x}$ can be expressed as (Miller and Blair, 2009):

$$
\mathbf{x}=\mathbf{A x}+\mathbf{f}
$$

where $\mathbf{A}$ is known as the technical coefficients matrix or direct requirements matrix. Using the Leontief's inverse function, the solution of eqn. 2 is given by $\mathbf{x}=\mathbf{L f}$, where $\mathbf{L}=(\mathbf{I}-\mathbf{A})^{-1}$ is called as the Leontief inverse (Leontief, 1970). In the MRIO analysis, the multiregional technical coefficients matrix is defined as:

$$
A=\left[\begin{array}{lll}
A^{r r} & A^{r s} & A^{r t} \\
A^{s r} & A^{s s} & A^{s t} \\
A^{t r} & A^{t s} & A^{t t}
\end{array}\right]
$$

$$
\text { where } \mathbf{A}^{\mathrm{rs}}=\mathbf{Z}^{\mathrm{rs}} \hat{\mathbf{X}}^{-\mathbf{1}}
$$

After that, Leontief matrix and Leontief inverse matrix are calculated using the eqn. 4 and 5, respectively:

$$
\begin{aligned}
& {[\mathbf{I}-\mathbf{A}]=\left[\begin{array}{ccc}
\mathbf{I}-\mathbf{A}^{\mathrm{rr}} & -\mathbf{A}^{\mathrm{rs}} & -\mathbf{A}^{\mathrm{rt}} \\
-\mathbf{A}^{\mathrm{sr}} & \mathbf{I}-\mathbf{A}^{\mathrm{ss}} & -\mathbf{A}^{\mathrm{st}} \\
-\mathbf{A}^{\mathrm{tr}} & -\mathbf{A}^{\mathrm{ts}} & \mathbf{I}-\mathbf{A}^{\mathrm{tt}}
\end{array}\right]} \\
& \mathbf{L}=[\mathbf{I}-\mathbf{A}]^{-1}=\left[\begin{array}{ccc}
\mathbf{I}-\mathbf{A}^{\mathrm{rr}} & -\mathbf{A}^{\mathrm{rs}} & -\mathbf{A}^{\mathrm{rt}} \\
-\mathbf{A}^{\text {sr }} & \mathbf{I}-\mathbf{A}^{\text {ss }} & -\mathbf{A}^{\text {st }} \\
-\mathbf{A}^{\mathrm{tr}} & -\mathbf{A}^{\mathbf{t s}} & \mathbf{I}-\mathbf{A}^{\mathrm{tt}}
\end{array}\right]^{-1}=\left[\begin{array}{lll}
\mathbf{B}^{\mathrm{rr}} & \mathbf{B}^{\mathrm{rs}} & \mathbf{B}^{\mathrm{rt}} \\
\mathbf{B}^{\text {sr }} & \mathbf{B}^{\text {ss }} & \mathbf{B}^{\text {st }} \\
\mathbf{B}^{\text {tr }} & \mathbf{B}^{\text {ts }} & \mathbf{B}^{\mathrm{tt}}
\end{array}\right]
\end{aligned}
$$

Furthermore, our MRIO model is extended with two environmental impact matrices, where $\mathbf{C}$ is a diagonal matrix of carbon emission coefficients and $\mathbf{E}$ is a diagonal matrix of energy use coefficients. Then, the total sectorial emissions and energy use are given by eqn. 6 and 7, respectively:

$$
\begin{aligned}
& \mathbf{c}=\mathbf{C B f} \\
& \mathbf{e}=\mathbf{E B f}
\end{aligned}
$$

where $\mathbf{c}$ is a column vector of total carbon emissions, and $\mathbf{e}$ is a column vector of total energy use. Hence, the sectorial emissions of a specific country $r$ are given in eqn. 8:

$$
c^{r}=C^{r} B^{r r} f^{r}+C^{r} B^{r s} f^{s}+C^{r} B^{r t} f^{t}
$$

Finally, the sectorial energy uses of a specific country $r$ are given in eqn. 9:

$$
e^{r}=E^{r} B^{r r} f^{r}+E^{r} B^{r s} f^{s}+E^{r} B^{r t} f^{t}
$$

\subsection{Data Collection and Preparation}

This paper gathered the majority of its dataset from the WIOD to obtain sectoral transactions table and GHG emissions and energy consumption data. The global warming potential (GWP) of each sector is calculated by multiplying the total GHG emission of each sector with conversion factors obtained from the United States Environmental Protection Agency (U.S EPA, 2013). The GHG emission dataset involves the direct carbon dioxide $\left(\mathrm{CO}_{2}\right)$, methane $\left(\mathrm{CH}_{4}\right)$ and nitrous oxide $\left(\mathrm{N}_{2} \mathrm{O}\right)$ emissions of each sector. The GWP results are presented in terms 
of metric tons of $\mathrm{CO}_{2}$-equivalent ( $\mathrm{mt} \mathrm{CO}_{2}$-eqv). Table 3 presents the GWPs of GHG emissions relative to $\mathrm{CO}_{2}$ for a 100 -year time horizon.

Table 3. Direct Global Warming Potentials relative to $\mathrm{CO}_{2}$ (U.S. EPA, 2013)

\begin{tabular}{lcc}
\hline Common Name & Chemical Formula & $\begin{array}{c}\text { Conversion factors of GWP } \\
\text { for 100-year time horizon }\end{array}$ \\
\hline Carbon Dioxide & $\mathrm{CO}_{2}$ & 1 \\
Methane & $\mathrm{CH}_{4}$ & 25 \\
Nitrous Oxide & $\mathrm{N}_{2} \mathrm{O}$ & 298 \\
\hline
\end{tabular}

For total energy consumption, the sectorial energy use data are obtained from the WIOD. The energy data include the total fossil and non-fossil gross energy use of each sector and presented in tera-joules (TJ). In order to prevent a double counting issue in energy accounts, we only summed up the primary energy carries (crude oil, coal, natural gas, nuclear energy, hydropower, and renewables), which are shown in the WIOD energy accounts. Similar approach was also used by Bortolamedi (2015) and the primary energy carriers and their WIOD codes are presented in Table 4. All matrix calculations are performed by using a MatLab programming software (MATLAB, 2012).

Table 4. Primary Energy Carriers in WIOD (Bortolamedi, 2015)

\begin{tabular}{lc}
\hline Primary Energy Carriers & WIOD Code \\
\hline Crude Oil & Crude \\
Coal & HCoal, BCoal, Coke \\
Natural Gas & NatGas, OthGas \\
Nuclear Energy & Nuclear \\
Hydropower & Hydro \\
Renewables & Waste, Biogasol, Biodiesel, Biogas, Geotherm, \\
& Solar, Wind, Othsourc \\
\hline
\end{tabular}

The followings briefly summarize the major research steps:

* First, total economic transaction table is obtained from the WIOD and total requirement matrix is created by using the Leontief's inverse,

* Second, total economic output of each sector from all countries are gathered. Then, by dividing GWP and energy use of sectors to corresponding economic output, we obtaine the $\mathbf{C}$ and $\mathbf{E}$ matrices. Each element of this matrices present the direct carbon and energy impact of 1435 sectors,

* Finally, by using the MRIO framework, we calculate the onsite, upstream and T+W+R related GWP and energy use of 16 major Turkish manufacturing sectors between 2000 and 2009.

\section{Results}

\subsection{Carbon footprint and energy use of manufacturing sectors and their supply chains}

Fig. 1 presents the total average carbon footprint and energy use of 16 manufacturing sectors based on per \$M and total economic output during the period between 2000 and 2009. The results show the contributions of upstream, onsite manufacturing and transportation $(\mathrm{T})$, wholesale $(\mathrm{W})$ and retail $(\mathrm{R})$ trade (hereafter called the "T $+\mathrm{W}+\mathrm{R}$ ") to carbon footprint and energy use inventory. Fig. 1a indicates that AHFF, FBT, TTP, ONMM, BMFM and CCP are the top- 6 industrial sectors based on total amount of carbon emissions. These sectors account for 
over $50 \%$ of the total carbon emissions in the MRIO economy. In terms of the contribution to the supply chain phases, onsite manufacturing activities were found to be dominant only for AHFF and ONMM. For the rest of the sectors, the industries in the upstream supply chains were found to be responsible for over $90 \%$ of the total impacts and the contribution of onsite and $\mathrm{T}+\mathrm{W}+\mathrm{R}$ activities were found to be minimal.

Fig. $1 \mathrm{~b}$ presents the total carbon footprint of 16 manufacturing sectors based on the per $\$ \mathrm{M}$ as an average of carbon footprints during the period between 2000 and 2009. The results showed that ONMM, WPWC, CRPNF, BMFM, $\mathrm{CCP}$, and RP were found to be as the top-6 industrial sectors based on total carbon footprints against per \$M output. These sectors were found to be responsible for around $60 \%$ of total carbon footprints. When we look at more closely at contribution of supply chain phases, onsite manufacturing activities were found to be the major driver of footprints only for AHFF, ONMM and WPWC. The same as total carbon footprint results, upstream supply chains are responsible for over $90 \%$ of the total impacts and the contribution of direct and $\mathrm{T}+\mathrm{W}+\mathrm{R}$ related supply chain phases are quite low. Although AHFF, FBT and TTP have the largest total carbon emissions based on total economic output, their carbon emissions based on $\$ \mathrm{M}$ output are found to be lower when compared to emissions based on total economic output. On the other hand, sectors with low total carbon footprints such as WPWC and CRPNF have the highest carbon emissions per \$M output. Among the major manufacturing sectors, ONMM sector is found to have high carbon emissions for both per \$M and total output. In both cases, LLF sector has the lowest carbon emissions when compared with other sectors.

Fig. 1c presents the total energy use of 16 manufacturing sectors based on total economic output as an average of total energy use for the period 2000 and 2009. The results showed that TTP, FBT, BMFM, CRPNF and AHFF represent the top- industrial sectors in total energy use category based on total economic output. The top sectors are found to be responsible for more than two third of total energy use. When we look at more closely at contribution of supply chain phases, onsite manufacturing is found to be dominant only for TTP and FBT. On the other hand, for the majority of the manufacturing sectors, upstream supply chains are responsible for over $65 \%$ of the total energy use. The contribution of direct and $\mathrm{T}+\mathrm{W}+\mathrm{R}$ related supply chain phases have a little contribution to overall energy use. LLF and WPWC are responsible for the least amount of energy in comparison with other sectors.

Fig. 1d shows the total carbon footprint of 16 manufacturing sectors based on per $\$ M$ activity. The results revealed that CRPNF, EOE, TTP, BMFM, and TE use the biggest energy resources within the manufacturing sectors. These sectors are found to have approximately more than 50\% of total energy use among the 16 manufacturing sectors. The results analyzing the contribution of supply chain phases to total energy use showed that onsite energy use of manufacturing is found to be dominant only for AHFF and ONMM. The same as total carbon footprint results, upstream supply chains were found to be responsible for over $90 \%$ of the total impacts. The contribution of direct and $\mathrm{T}+\mathrm{W}+\mathrm{R}$ related supply chain phases were seen as having nonsignificant impact share. It is also important to emphasize that FBT is found to be as the second largest energy consumer; however its total energy use based on per $\$ \mathrm{M}$ economic output was found to be lower compared to total energy use. Furthermore, sectors with high total energy use such as TTP and BMFM have the high energy use for both per \$M and economic output basis. Among the major manufacturing sectors, AHFF sector was found to be among the top-5 energy consumer based on total economic activity. However, the total energy use of AHFF based on per \$M economic output was observed as the lowest when compared to other sectors. 







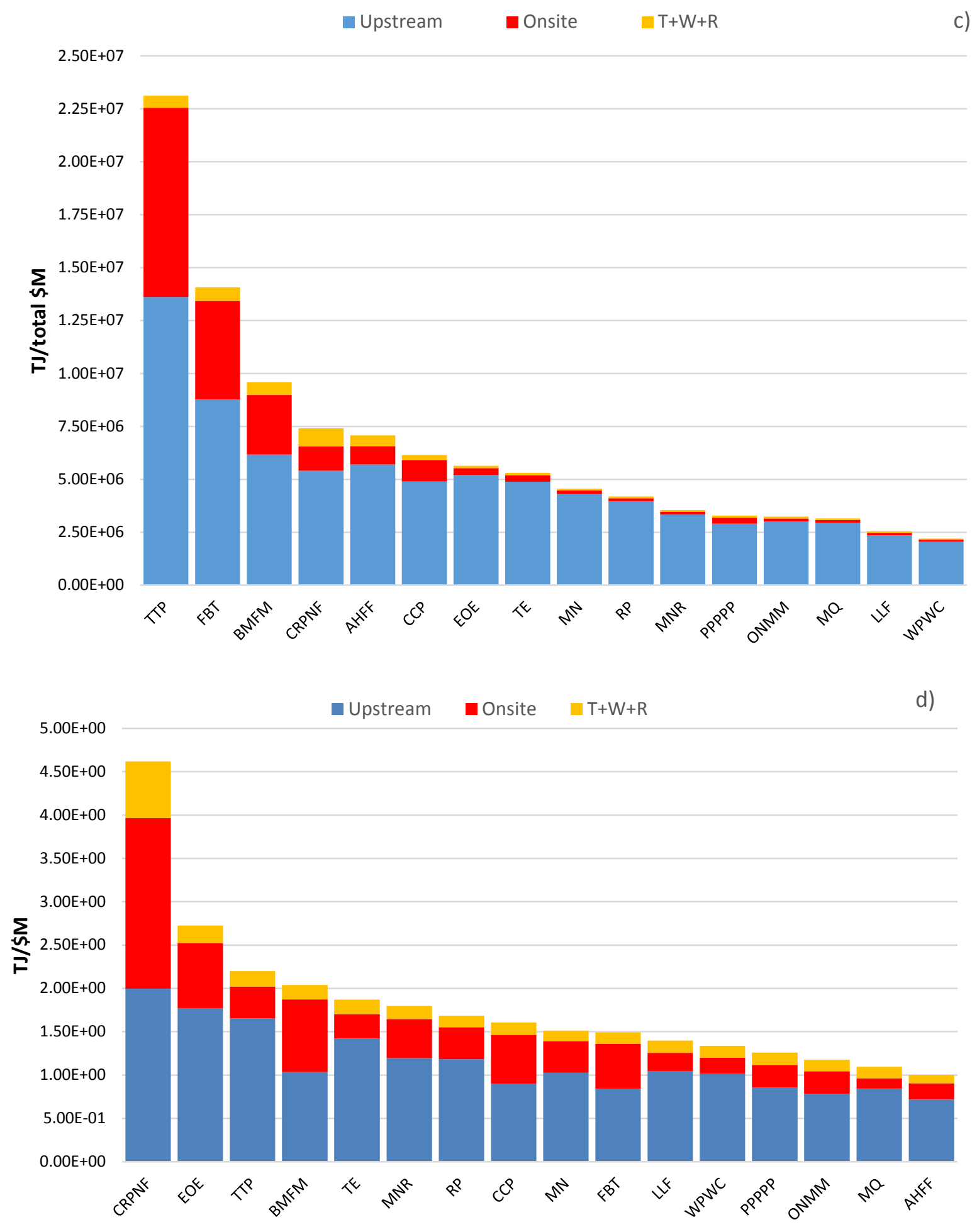

Fig 1. Average carbon footprint and energy use of major manufacturing sectors a) carbon footprint based on total output ( $\mathrm{t} \mathrm{CO}_{2}$-eqv/total $\left.\$ \mathrm{M}\right)$ b) carbon footprint based on per $\$ \mathrm{M}$ output ( $\mathrm{CO}_{2}$-eqv/ $\$ \mathrm{M}$ ) c) energy use based on total output (TJ/total \$M) d) energy use based on per \$M output (TJ/ \$M)

Fig. 2 depicts the contribution of each supply chain phase to carbon footprint and energy use extents. This analysis is important to understand the degree of nexus between supply chain phases for carbon footprint and energy 
utilization. The results showed that the percentage contribution of upstream suppliers, onsite manufacturing and $\mathrm{T}+\mathrm{W}+\mathrm{R}$ phases were found to be similar for the sectors of BMFM, CRPNF, EOE, LLF, MN, MNR and TE for both carbon and energy categories. For these sectors, upstream supply chain impacts were found to be dominant compared to onsite manufacturing activities and $\mathrm{T}+\mathrm{W}+\mathrm{R}$. For the manufacturing sectors such as AHFF, CCP, FBT, MQ, ONMM and WPWC, the contributions of different supply chain phases to total carbon emissions and energy use were found to be substantially different. For instance, upstream supply chains were found to be highly dominant in the total energy use of three manufacturing sectors: AHFF, ONMM, and WPWC. On the other hand, onsite manufacturing activities were found to have the biggest carbon emissions for these sectors in comparison with upstream supply chains and $\mathrm{T}+\mathrm{W}+\mathrm{R}$ phases. For $\mathrm{CCP}$ and MQ sectors, upstream supply chains were found to be the major driver of total energy use; whereas upstream supply chains and onsite manufacturing equally shared the total carbon emissions. For FBT, which is the second largest manufacturing sector in terms of total energy use and carbon emissions, upstream supply chains were found to be highly dominant and the percentage contribution of transportation and $\mathrm{T}+\mathrm{W}+\mathrm{R}$ phases are responsible for the minimum share of total impacts. On the average, the contribution of upstream supply chains to total energy use of the majority (75\%) of the manufacturing sectors was found to $80 \%$ or higher.

In carbon emissions category, only four sectors' impacts were found to be driven by the onsite manufacturing activities and the rest of the sectors' impacts (accounts for $75 \%$ of all sectors) were found to have the largest shares attributed to the upstream supply chain industries. For most of the sectors with an exception of CRPNF, the contribution of $\mathrm{T}+\mathrm{W}+\mathrm{R}$ was found to have less than $5 \%$ of overall carbon emissions and energy use. 


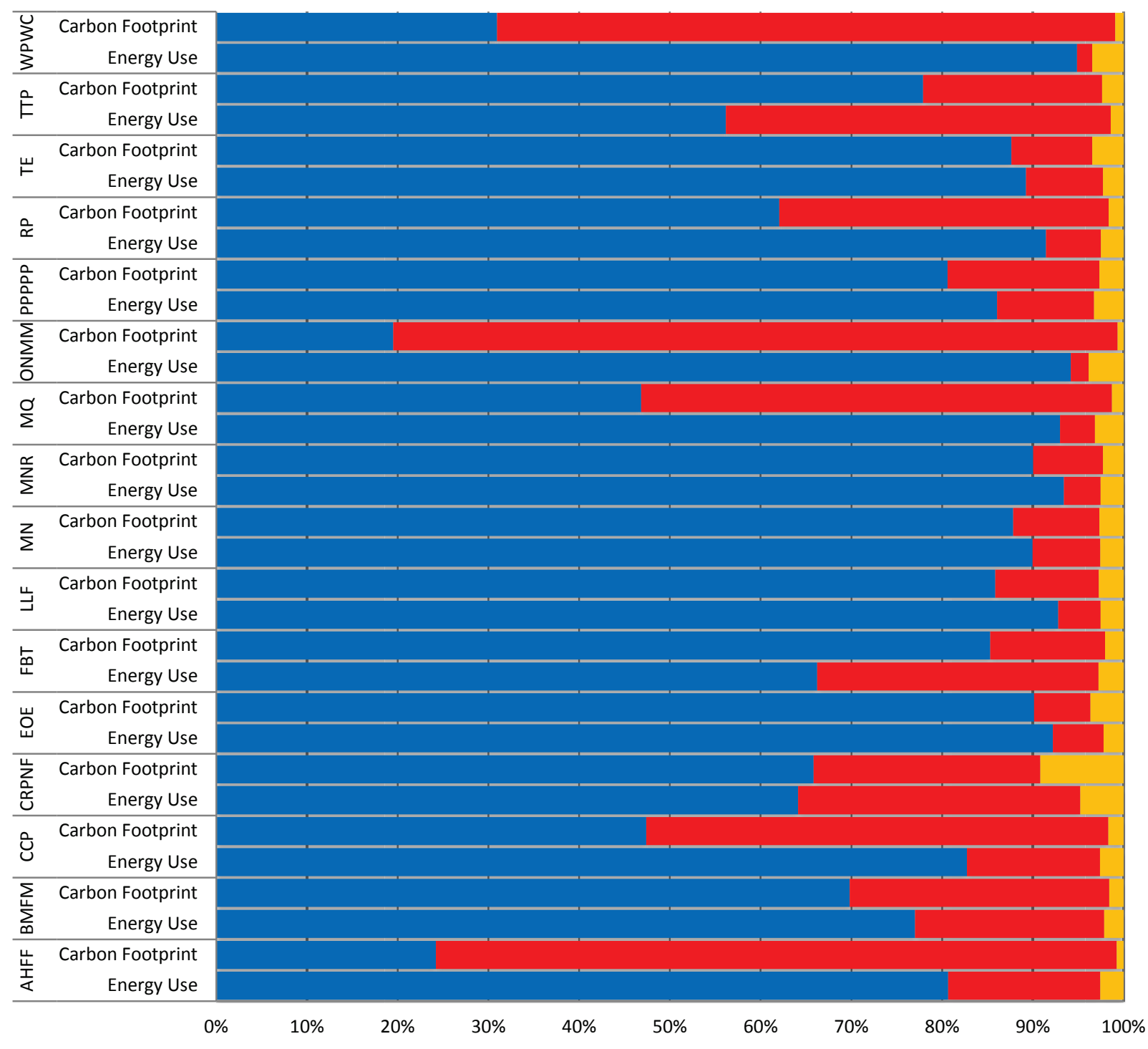

Fig 2. Contribution of upstream, onsite and $\mathrm{T}+\mathrm{W}+\mathrm{R}$ phases to total energy use and carbon footprint of 16 Turkish manufacturing sectors (average of 2000 and 2009)

After analyzing the direct and supply chain components as two major groups, it is important to analyze the impact share of each of the sectors in the upstream supply chains to the total energy and carbon impacts. Therefore, a supply chain decompositions analysis was utilized to trace the effect of top-5 upstream suppliers (here, the top 5 sector phrase indicates the five sectors with the greatest shares in the upstream supply chain-related impacts). Table 5 shows the upstream supply chains sectors' contribution to carbon emissions based on total economic output. AHFF, FBT, TTP, ONMM and BMFM industries were found to be emitting the largest amount of carbon emissions compared to the remaining 11 sectors. Among these sectors, total carbon footprint of AHFF and ONMM was found to be largely driven by onsite activities; whereas upstream supply chains of BMFM, FBT, and TTP were found to be responsible for the greatest shares in terms of total carbon footprint. For AHFF and ONMM; the percentage shares of onsite manufacturing activities were found to be $75 \%$ and $80 \%$, respectively. For BMFM, FBT, and TTP; upstream supplier industries accounted for around 70.2\%, 87.4\%, and 80.3\% of total carbon footprint inventory. After a detailed analysis of top-5 driving sectors' supply chain-linked impacts; Electricity, 
Gas and Water Supply sector was mostly found to be as the main contributor to total carbon emissions. For instance, the carbon footprint shares of Electricity, Gas and Water Supply industry within the total supply chainlinked impacts of ONMM, BMFM and TTP were found to be critically high, accounting for $42.3 \%, 38.2 \%$ and $33.65 \%$ of total supply chain-related carbon emissions. On the contrary, inland transportation was found to have the least amount of carbon emissions with less than 5\% impact share.

Table 6 depicts the upstream supply chains sectors' contribution to carbon emissions based on per \$M economic activity. ONMM, WPWC, CRPNF, BMFM and CCP were found to have the highest carbon emissions per \$M economic output. Among these sectors, carbon footprint of ONMM, WPWC and CCP is largely driven by onsite activities whereas upstream supply chains of CRPNF and BMFM were found to be responsible for the biggest share of the total carbon footprint. For ONMM, WPWC and CCP, the percentage shares of direct impacts were found to be as $75 \%$ and $80 \%$, respectively. For BMFM, FBT and TTP, upstream suppliers accounted for around $80 \%, 68.9 \%$ and $53.2 \%$ of total carbon footprint based on per $\$ M$ output. When analyzing top-5 contributors in upstream supply chains, Electricity, Gas and Water Supply sector was again found to be as the main contributor of the total carbon emissions. The share of the Electricity, Gas and Water Supply among the upstream suppliers ONMM, WPWC, CRPNF, and BMFM had the greatest values, accounting for $41.9 \%, 29.2 \%, 33.5 \%$, and 38.3 of total supply chain-related carbon impacts. The same as overall carbon emissions based on total economic output, inland transportation had the least amount of carbon emissions, which account for less than $5 \%$ of total carbon emissions with an exception of CRPNF. For this sector, the percentage contribution of transportation sector was found to be approximately $15 \%$ of total upstream carbon footprints.

Table 7 presents the upstream supply chains sectors' contribution to energy use based on total economic output. TTP, FBT, BMFM, CRPNF and AHFF had the highest energy use when compared to other manufacturing sectors. The total energy consumption of these sectors was mainly driven by upstream supply chains whereas onsite manufacturing sectors have the least amount of energy use. For AHFF and BMFM, the percentage shares of onsite manufacturing were found to be noncritical, accounting for $13.38 \%$ and $17.23 \%$ of the total energy use, respectively. For TTP, FBT and CRPNF, upstream suppliers accounted for approximately 47.36\%, 64.36\% and $73.26 \%$ of total energy consumption. The Coke, Refined Petroleum and Nuclear Fuel sector was usually found to be as the main driver of energy use in upstream supply chains. For example, the share of Coke, Refined Petroleum and Nuclear Fuel within the supply chain paths of AHFF, CRPNF and FBT had the following energy use shares: $19.78 \%, 7.12 \%$ and $11.27 \%$, respectively. In contrast, the percentage contribution of transportation and trade activities were not listed among the top-5 upstream suppliers for the energy use category.

Lastly, Table 8 shows the contribution of upstream suppliers to total energy consumption based on per \$M economic activity. The results revealed that CRPNF, EOE, TTP, BMFM and TE have the highest energy use against per \$M economic output. For these manufacturing sectors, total energy use was only dominated by upstream suppliers. Especially, the upstream supply chain portions of energy use are the highest for EOE and TE which are $96.34 \%$ and $90.31 \%$ of total energy use. For BMFM, CRPNF and TTP, the percentage shares of onsite manufacturing are $17.98 \%, 27.29 \%$ and $53.72 \%$, respectively. When the researchers analyzed the drivers of upstream supply chains, the Coke, Refined Petroleum and Nuclear Fuel sector is again observed as the main contributor. The share of the Coke, Refined Petroleum and Nuclear Fuel among the upstream suppliers including CRPNF, TTP and BMFM had the highest shares, which were found as $7.63 \%, 7.73 \%$ and $6.60 \%$ of the total upstream energy consumption. 
Table 5. Supply chain decomposition analysis of carbon footprint for top 5 sectors based on total output

\begin{tabular}{|c|c|}
\hline AHFF & Share $(\%)$ \\
\hline Avg. Onsite Carbon Footprint & $75.0 \%$ \\
\hline Avg. Supply Chain Carbon Footprint & $25.0 \%$ \\
\hline \multicolumn{2}{|l|}{ Top 5 Sectors in Supply Chains } \\
\hline Electricity, Gas and Water Supply & $29.5 \%$ \\
\hline Agriculture, Hunting, Forestry and Fishing & $17.8 \%$ \\
\hline Chemicals and Chemical Products & $11.6 \%$ \\
\hline Mining and Quarrying & $8.1 \%$ \\
\hline Coke, Refined Petroleum and Nuclear Fuel & $7.3 \%$ \\
\hline \multicolumn{2}{|l|}{ FBT } \\
\hline Avg. Onsite Carbon Footprint & $12.6 \%$ \\
\hline Avg. Supply Chain Carbon Footprint & $87.4 \%$ \\
\hline \multicolumn{2}{|l|}{ Top 5 Sectors in Supply Chains } \\
\hline Agriculture, Hunting, Forestry and Fishing & $56.1 \%$ \\
\hline Electricity, Gas and Water Supply & $15.4 \%$ \\
\hline Chemicals and Chemical Products & $4.5 \%$ \\
\hline Mining and Quarrying & $3.7 \%$ \\
\hline Other Non-Metallic Mineral & $3.5 \%$ \\
\hline \multicolumn{2}{|l|}{ TTP } \\
\hline Avg. Onsite Carbon Footprint & $19.7 \%$ \\
\hline Avg. Supply Chain Carbon Footprint & $80.3 \%$ \\
\hline \multicolumn{2}{|l|}{ Top 5 Sectors in Supply Chains } \\
\hline Electricity, Gas and Water Supply & $33.6 \%$ \\
\hline Chemicals and Chemical Products & $14.7 \%$ \\
\hline Agriculture, Hunting, Forestry and Fishing & $12.1 \%$ \\
\hline Mining and Quarrying & $7.1 \%$ \\
\hline Inland Transport & $4.2 \%$ \\
\hline \multicolumn{2}{|l|}{ ONMM } \\
\hline Avg. Onsite Carbon Footprint & $80.0 \%$ \\
\hline Avg. Supply Chain Carbon Footprint & $20.0 \%$ \\
\hline \multicolumn{2}{|l|}{ Top 5 Sectors in Supply Chains } \\
\hline Electricity, Gas and Water Supply & $42.3 \%$ \\
\hline Mining and Quarrying & $20.3 \%$ \\
\hline Chemicals and Chemical Products & $6.3 \%$ \\
\hline Other Non-Metallic Mineral & $4.9 \%$ \\
\hline Inland Transport & $4.5 \%$ \\
\hline \multicolumn{2}{|l|}{ BMFM } \\
\hline Avg. Onsite Carbon Footprint & $29.8 \%$ \\
\hline Avg. Supply Chain Carbon Footprint & $70.2 \%$ \\
\hline \multicolumn{2}{|l|}{ Top 5 Sectors in Supply Chains } \\
\hline Electricity, Gas and Water Supply & $38.2 \%$ \\
\hline Basic Metals and Fabricated Metal & $24.1 \%$ \\
\hline Mining and Quarrying & $9.9 \%$ \\
\hline Other Non-Metallic Mineral & $8.3 \%$ \\
\hline Inland Transport & $3.2 \%$ \\
\hline
\end{tabular}


Table 6. Supply chain decomposition analysis of carbon footprint for top 5 sectors based on per $\$ M$ output

\begin{tabular}{|c|c|}
\hline ONMM & Share $(\%)$ \\
\hline Avg. Onsite Carbon Footprint & $80.0 \%$ \\
\hline Avg. Supply Chain Carbon Footprint & $20.0 \%$ \\
\hline \multicolumn{2}{|l|}{ Top 5 Sectors in Supply Chains } \\
\hline Electricity, Gas and Water Supply & $41.9 \%$ \\
\hline Mining and Quarrying & $21.1 \%$ \\
\hline Chemicals and Chemical Products & $6.7 \%$ \\
\hline Inland Transport & $4.6 \%$ \\
\hline Coke, Refined Petroleum and Nuclear Fuel & $4.2 \%$ \\
\hline \multicolumn{2}{|l|}{ WPWC } \\
\hline Avg. Onsite Carbon Footprint & $68.9 \%$ \\
\hline Avg. Supply Chain Carbon Footprint & $31.1 \%$ \\
\hline \multicolumn{2}{|l|}{ Top 5 Sectors in Supply Chains } \\
\hline Electricity, Gas and Water Supply & $29.2 \%$ \\
\hline Agriculture, Hunting, Forestry and Fishing & $27.1 \%$ \\
\hline Chemicals and Chemical Products & $13.4 \%$ \\
\hline Mining and Quarrying & $6.7 \%$ \\
\hline Inland Transport & $3.5 \%$ \\
\hline \multicolumn{2}{|l|}{ CRPNF } \\
\hline Avg. Onsite Carbon Footprint & $25.1 \%$ \\
\hline Avg. Supply Chain Carbon Footprint & $74.9 \%$ \\
\hline \multicolumn{2}{|l|}{ Top 5 Sectors in Supply Chains } \\
\hline Mining and Quarrying & $34.8 \%$ \\
\hline Electricity, Gas and Water Supply & $33.5 \%$ \\
\hline Inland Transport & $15.0 \%$ \\
\hline Coke, Refined Petroleum and Nuclear Fuel & $3.0 \%$ \\
\hline Basic Metals and Fabricated Metal & $2.4 \%$ \\
\hline \multicolumn{2}{|l|}{ BMFM } \\
\hline Avg. Onsite Carbon Footprint & $29.8 \%$ \\
\hline Avg. Supply Chain Carbon Footprint & $70.2 \%$ \\
\hline \multicolumn{2}{|l|}{ Top 5 Sectors in Supply Chains } \\
\hline Electricity, Gas and Water Supply & $38.3 \%$ \\
\hline Basic Metals and Fabricated Metal & $23.2 \%$ \\
\hline Mining and Quarrying & $10.1 \%$ \\
\hline Other Non-Metallic Mineral & $8.5 \%$ \\
\hline Inland Transport & $3.2 \%$ \\
\hline \multicolumn{2}{|l|}{ CCP } \\
\hline Avg. Onsite Carbon Footprint & $53.2 \%$ \\
\hline Avg. Supply Chain Carbon Footprint & $46.8 \%$ \\
\hline \multicolumn{2}{|l|}{ Top 5 Sectors in Supply Chains } \\
\hline Electricity, Gas and Water Supply & $28.6 \%$ \\
\hline Chemicals and Chemical Products & $17.5 \%$ \\
\hline Mining and Quarrying & $13.2 \%$ \\
\hline Agriculture, Hunting, Forestry and Fishing & $6.6 \%$ \\
\hline Other Non-Metallic Mineral & $5.5 \%$ \\
\hline
\end{tabular}


Table 7. Supply chain decomposition analysis of energy use for top 5 sectors for total economic outputs

\begin{tabular}{|c|c|}
\hline 1.TTP & Share $(\%)$ \\
\hline Average Onsite Carbon Footprint & $52.64 \%$ \\
\hline Average Supply Chain Carbon Footprint & $47.36 \%$ \\
\hline \multicolumn{2}{|l|}{ Top 5 Sectors in Supply Chains } \\
\hline Textiles and Textile Products & $9.27 \%$ \\
\hline Coke, Refined Petroleum and Nuclear Fuel & $6.84 \%$ \\
\hline Chemicals and Chemical Products & $6.23 \%$ \\
\hline Renting of M\&Eq and Other Business Activities & $4.57 \%$ \\
\hline Mining and Quarrying & $4.20 \%$ \\
\hline \multicolumn{2}{|l|}{ 2.FBT } \\
\hline Average Onsite Carbon Footprint & $35.64 \%$ \\
\hline Average Supply Chain Carbon Footprint & $64.36 \%$ \\
\hline \multicolumn{2}{|l|}{ Top 5 Sectors in Supply Chains } \\
\hline Coke, Refined Petroleum and Nuclear Fuel & $11.72 \%$ \\
\hline Food, Beverages and Tobacco & $7.45 \%$ \\
\hline Renting of M\&Eq and Other Business Activities & $4.53 \%$ \\
\hline Chemicals and Chemical Products & $4.18 \%$ \\
\hline Mining and Quarrying & $4.69 \%$ \\
\hline \multicolumn{2}{|l|}{ 3.BMFM } \\
\hline Average Onsite Carbon Footprint & $17.23 \%$ \\
\hline Average Supply Chain Carbon Footprint & $82.77 \%$ \\
\hline \multicolumn{2}{|l|}{ Top 5 Sectors in Supply Chains } \\
\hline Basic Metals and Fabricated Metal & $17.46 \%$ \\
\hline Mining and Quarrying & $9.14 \%$ \\
\hline Renting of M\&Eq and Other Business Activities & $7.88 \%$ \\
\hline Coke, Refined Petroleum and Nuclear Fuel & $5.20 \%$ \\
\hline Wholesale Trade and Commission Trade, Except of Motor Vehicles and Motorcycles & $3.09 \%$ \\
\hline \multicolumn{2}{|l|}{ 4.CRPNF } \\
\hline Average Onsite Carbon Footprint & $26.74 \%$ \\
\hline Average Supply Chain Carbon Footprint & $73.26 \%$ \\
\hline \multicolumn{2}{|l|}{ Top 5 Sectors in Supply Chains } \\
\hline Mining and Quarrying & $26.40 \%$ \\
\hline Coke, Refined Petroleum and Nuclear Fuel & $7.12 \%$ \\
\hline Wholesale Trade and Commission Trade, Except of Motor Vehicles and Motorcycles & $3.49 \%$ \\
\hline Renting of M \& Eq and Other Business Activities & $1.43 \%$ \\
\hline Inland Transport & $1.02 \%$ \\
\hline \multicolumn{2}{|l|}{ 5.AHFF } \\
\hline Average Onsite Carbon Footprint & $13.38 \%$ \\
\hline Average Supply Chain Carbon Footprint & $86.62 \%$ \\
\hline \multicolumn{2}{|l|}{ Top 5 Sectors in Supply Chains } \\
\hline Coke, Refined Petroleum and Nuclear Fuel & $19.78 \%$ \\
\hline Chemicals and Chemical Products & $6.19 \%$ \\
\hline Mining and Quarrying & $7.24 \%$ \\
\hline Food, Beverages and Tobacco & $4.76 \%$ \\
\hline Renting of $\mathrm{M} \& \mathrm{Eq}$ and Other Business Activities & $4.22 \%$ \\
\hline
\end{tabular}


Table 8. Supply chain decomposition analysis of energy use for top 5 sectors based on per $\$ M$ output

\begin{tabular}{|c|c|}
\hline 1.CRPNF & Share $(\%)$ \\
\hline Average Onsite Carbon Footprint & $27.29 \%$ \\
\hline Average Supply Chain Carbon Footprint & $72.71 \%$ \\
\hline \multicolumn{2}{|l|}{ Top 5 Sectors in Supply Chains } \\
\hline Mining and Quarrying & $27.94 \%$ \\
\hline Coke, Refined Petroleum and Nuclear Fuel & $7.63 \%$ \\
\hline Wholesale Trade and Commission Trade, Except of Motor Vehicles and Motorcycles & $3.84 \%$ \\
\hline Renting of M\&Eq and Other Business Activities & $1.63 \%$ \\
\hline Inland Transport & $1.09 \%$ \\
\hline \multicolumn{2}{|l|}{ 2.EOE } \\
\hline Average Onsite Carbon Footprint & $3.66 \%$ \\
\hline Average Supply Chain Carbon Footprint & $96.34 \%$ \\
\hline \multicolumn{2}{|l|}{ Top 5 Sectors in Supply Chains } \\
\hline Electrical and Optical Equipment & $31.75 \%$ \\
\hline Basic Metals and Fabricated Metal & $9.10 \%$ \\
\hline Renting of M\&Eq and Other Business Activities & $6.46 \%$ \\
\hline Coke, Refined Petroleum and Nuclear Fuel & $5.52 \%$ \\
\hline Chemicals and Chemical Products & $4.01 \%$ \\
\hline \multicolumn{2}{|l|}{ 3.TTP } \\
\hline Average Onsite Carbon Footprint & $53.72 \%$ \\
\hline Average Supply Chain Carbon Footprint & $46.28 \%$ \\
\hline \multicolumn{2}{|l|}{ Top 5 Sectors in Supply Chains } \\
\hline Textiles and Textile Products & $8.90 \%$ \\
\hline Coke, Refined Petroleum and Nuclear Fuel & $7.73 \%$ \\
\hline Chemicals and Chemical Products & $6.98 \%$ \\
\hline Renting of M\&Eq and Other Business Activities & $4.88 \%$ \\
\hline Mining and Quarrying & $4.50 \%$ \\
\hline \multicolumn{2}{|l|}{ 4.BMFM } \\
\hline Average Onsite Carbon Footprint & $17.98 \%$ \\
\hline Average Supply Chain Carbon Footprint & $82.11 \%$ \\
\hline \multicolumn{2}{|l|}{ Top 5 Sectors in Supply Chains } \\
\hline Basic Metals and Fabricated Metal & $18.09 \%$ \\
\hline Mining and Quarrying & $9.95 \%$ \\
\hline Fuel Renting of M\&Eq and Other Business Activities & $8.05 \%$ \\
\hline Coke, Refined Petroleum and Nuclear & $6.60 \%$ \\
\hline Wholesale Trade and Commission Trade, Except of Motor Vehicles and Motorcycles & $4.71 \%$ \\
\hline \multicolumn{2}{|l|}{ 5.TE } \\
\hline Average Onsite Carbon Footprint & $9.69 \%$ \\
\hline Average Supply Chain Carbon Footprint & $90.31 \%$ \\
\hline \multicolumn{2}{|l|}{ Top 5 Sectors in Supply Chains } \\
\hline Transport Equipment & $19.59 \%$ \\
\hline Basic Metals and Fabricated Metal & $13.67 \%$ \\
\hline Renting of M\&Eq and Other Business Activities & $8.56 \%$ \\
\hline Coke, Refined Petroleum and Nuclear Fuel & $6.46 \%$ \\
\hline Mining and Quarrying & $4.17 \%$ \\
\hline
\end{tabular}

The aforementioned analysis indicates that the total carbon and energy impacts of sectors were largely attributed to the upstream suppliers and onsite activities; whereas $\mathrm{T}+\mathrm{W}+\mathrm{R}$ have the lowest contribution. Although these sectors have a little contribution, Fig. 3 presented the contribution of transportation and trade activities to the total energy consumption for the top-5 manufacturing sectors: TTP, FBT, BMFM, CRPNF and AHFF. The results indicated that inland transportation had higher share compared to water and air transportation. On average, the share of transportation was found to be $50 \%$ or over among the downstream supply chain phases. The wholesale and retail trade phases had lower impact share than inland transportation with an exception of CRPNF sector. For this sector, until 2007, wholesale trade had the biggest share compared to retail trade and all other transportation 
sectors. In general, the total share of transportation phase started to increase during the period between 2008 and 2009, and showed a decreasing trend for wholesale and retail trade. This proved the growing dependency of manufacturing sectors to inland transportation sector, mainly the truck mode. The contribution of air transport was found to have a minimal impact in comparison with inland air transportation.

Fig. 4 represents the contribution of air, water and inland transport, wholesale and retail trade to total carbon emissions. The sectors presented in Fig. 4 were the ones which had the highest total carbon footprints between 2000 and 2009. The results showed that inland and water transportation modes had the biggest carbon emissions whereas the share of air transport in carbon emissions is found to be minimal. After air transportation, retail and wholesale trade were found to have the lowest portion of total carbon footprint. For ONMM, the share of inland transportation in total emissions was observed as the largest. On the other hand, the water transportation's share in carbon footprint of AHFF and FBT was found to be as highly dominant compared to other transportation sectors and trade activities. Overall, the percentage share of transportation modes and trade activities were not changed significantly between 2000 and 2009 period. Although water transportation was found to be responsible for the lowest energy use; its contribution to total carbon emissions was found to be quite high. 
Fig 3. Contribution of transportation and trade activities for energy use of top- 5 sectors based on total energy use

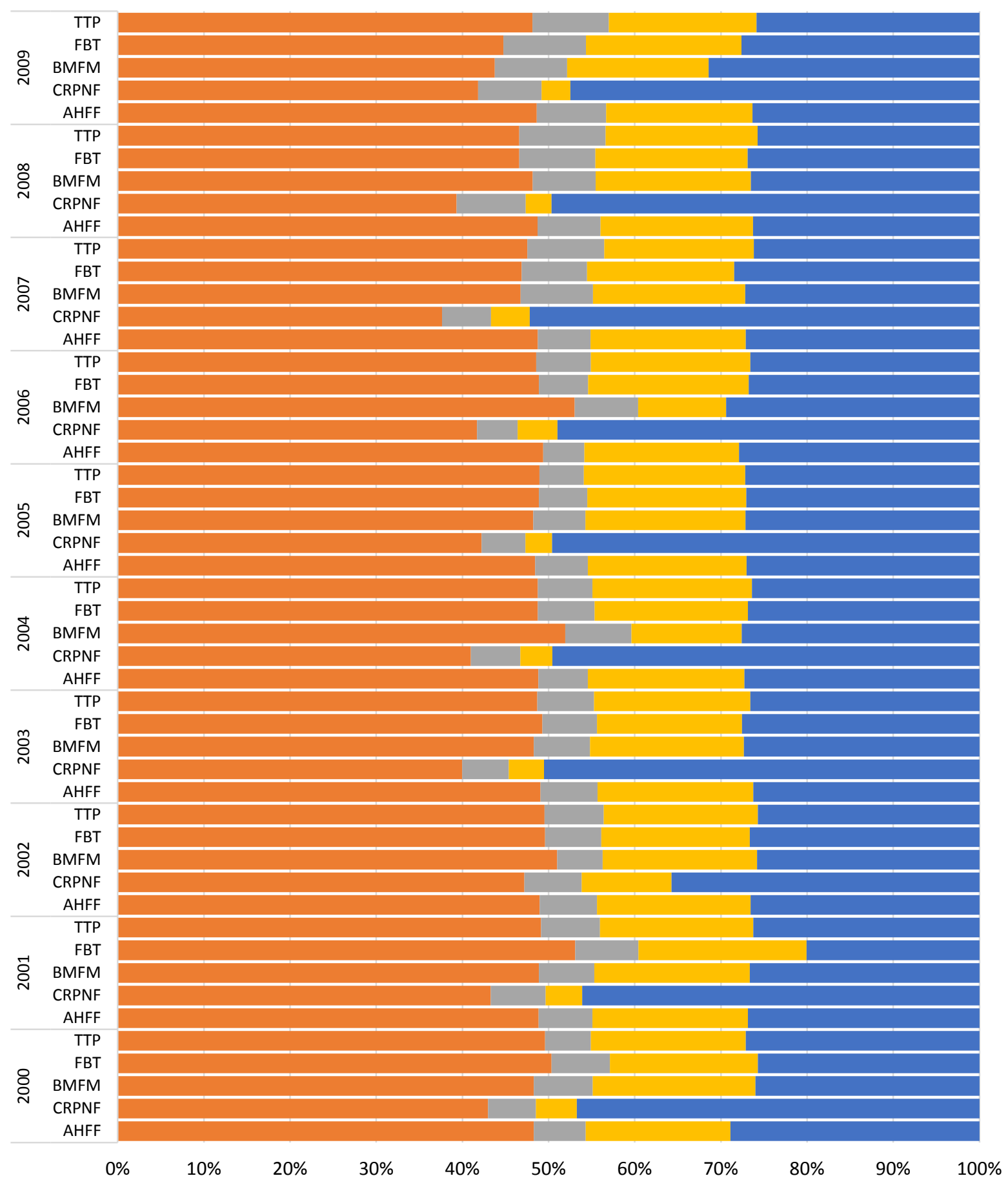

- Air Transport

- Inland Transport

Water Transport

Retail Trade, Expect of vehicles and motorcycles, repair of household goods

Wholesale Trade and commission Trade,Expect of Motor vechiels and Motorcycles

(average of 2000 and 2009) 

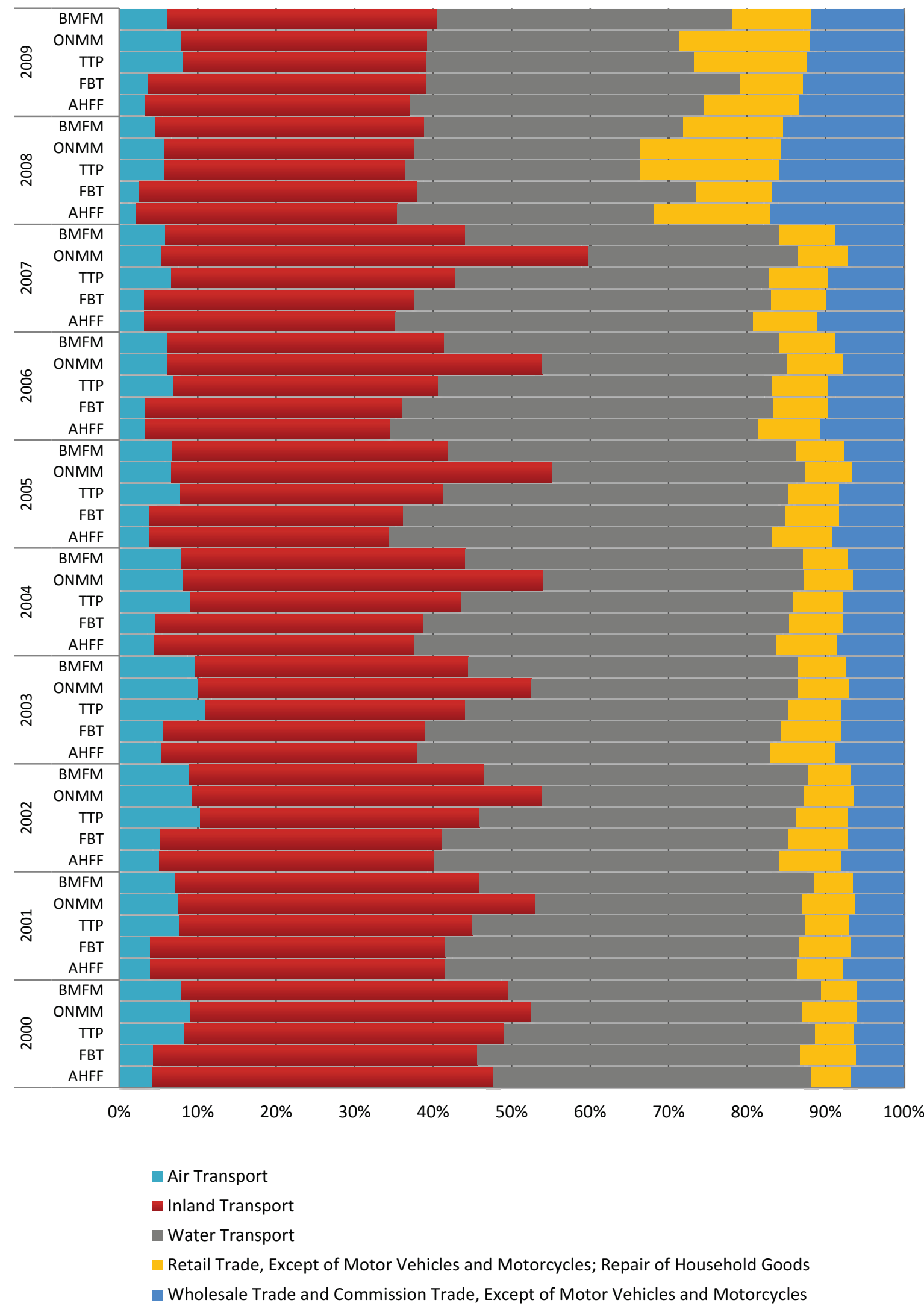

Fig 4. Contribution of transportation and trade activities for carbon footprint of top-5 sectors based on total carbon footprint (average of 2000 and 2009) 


\subsection{Global distribution of energy use and carbon footprint}

Fig. 5 presents the global carbon and energy distribution of each sector based on major world countries and RoW. For carbon emissions, the results showed that Indonesia (IDN), Russia (RUS), and RoW had the largest share in total carbon emissions. For TTP and EOE sectors, China (CHN) was also listed among the major contributing countries such as IND, RUS, and RoW. Overall, the carbon footprints of majority of manufacturing sectors were found in Turkish region and the RUS, CHN, and RoW were listed after Turkey (TUR) as major contributors. Among the manufacturing sectors, FBT had the highest regional carbon emissions and the contribution of global supply chains are found to be lower compared to other countries (see Fig 5a). The situation was also similar for MQ industry and the highest portion of carbon emission were located in TUR. As an important finding, for CRPNF sector, RUS was found to have the largest carbon emissions due to high dependence of Turkey to Russian energy.

Fig $5 \mathrm{~b}$ shows the share of world countries in total energy use of each manufacturing sector. The RoW was found to have the largest share in total global energy footprint of all manufacturing sectors. This is because TUR is a highly energy dependent country and imported the significant amount of its energy demand from neighbor countries such as Iran, Iraq, Azerbaijan, etc. Overall, CHN, Deutschland (DEU), TUR and USA were the most dominant countries based on total global energy use of Turkish manufacturing. Especially, the China's contribution to the total energy footprint is observed as the highest for TTP and EOE sectors. This was an expected result due to high import of textile and electronic products produced in CHN to Turkey. For the majority of manufacturing sectors, the contribution of Turkish energy production sector was around $10 \%$ of the total produced energy worldwide. Interestingly, the share of USA in total energy footprint of each manufacturing sector was found to be close enough to the share of Turkey. The results also showed that the energy shares of other world countries such as GBR, ITA, JPN, NLD, KOR and RUS were ranged between 1\% and 5\% and did not show significant variations among the production sectors.

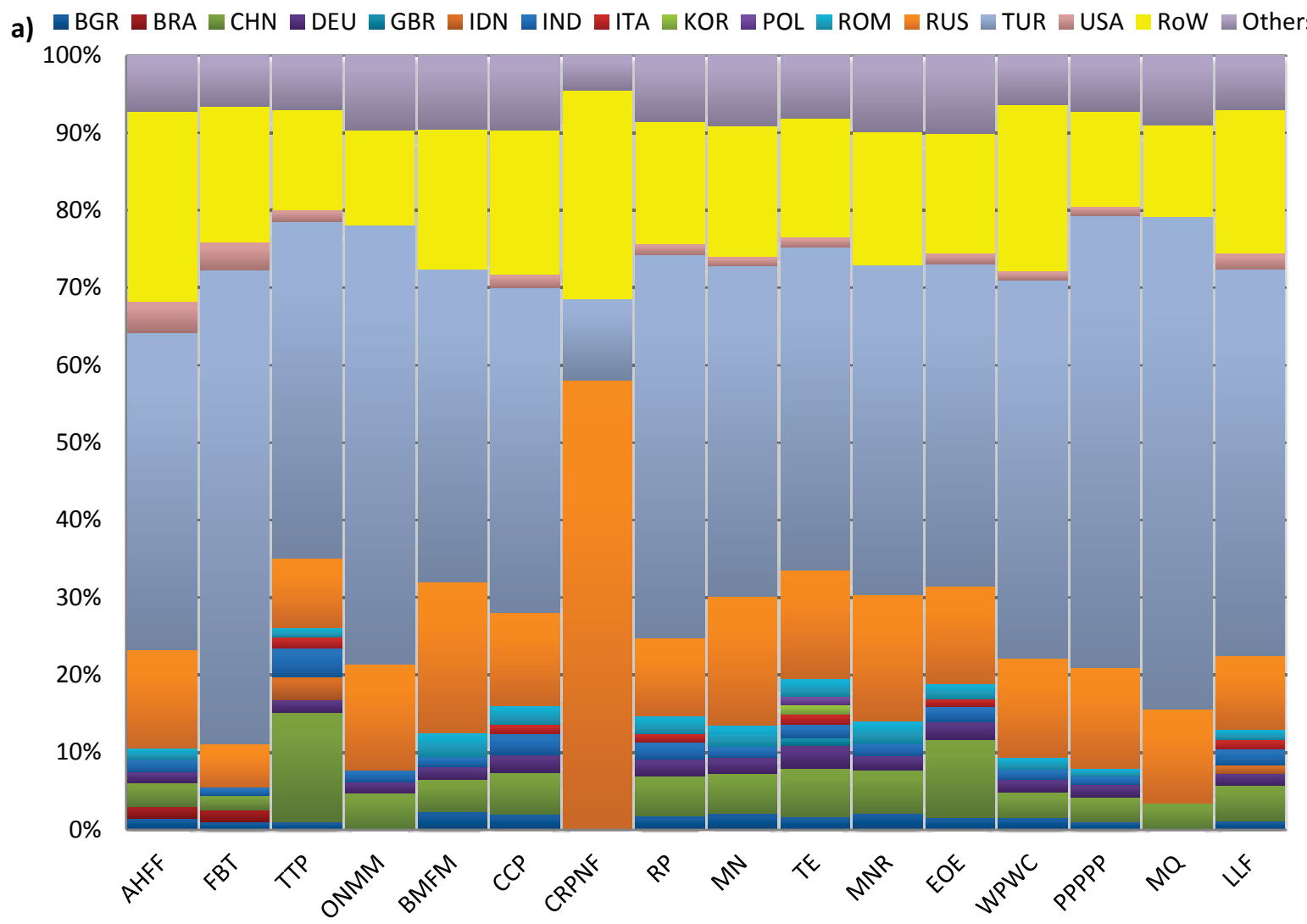




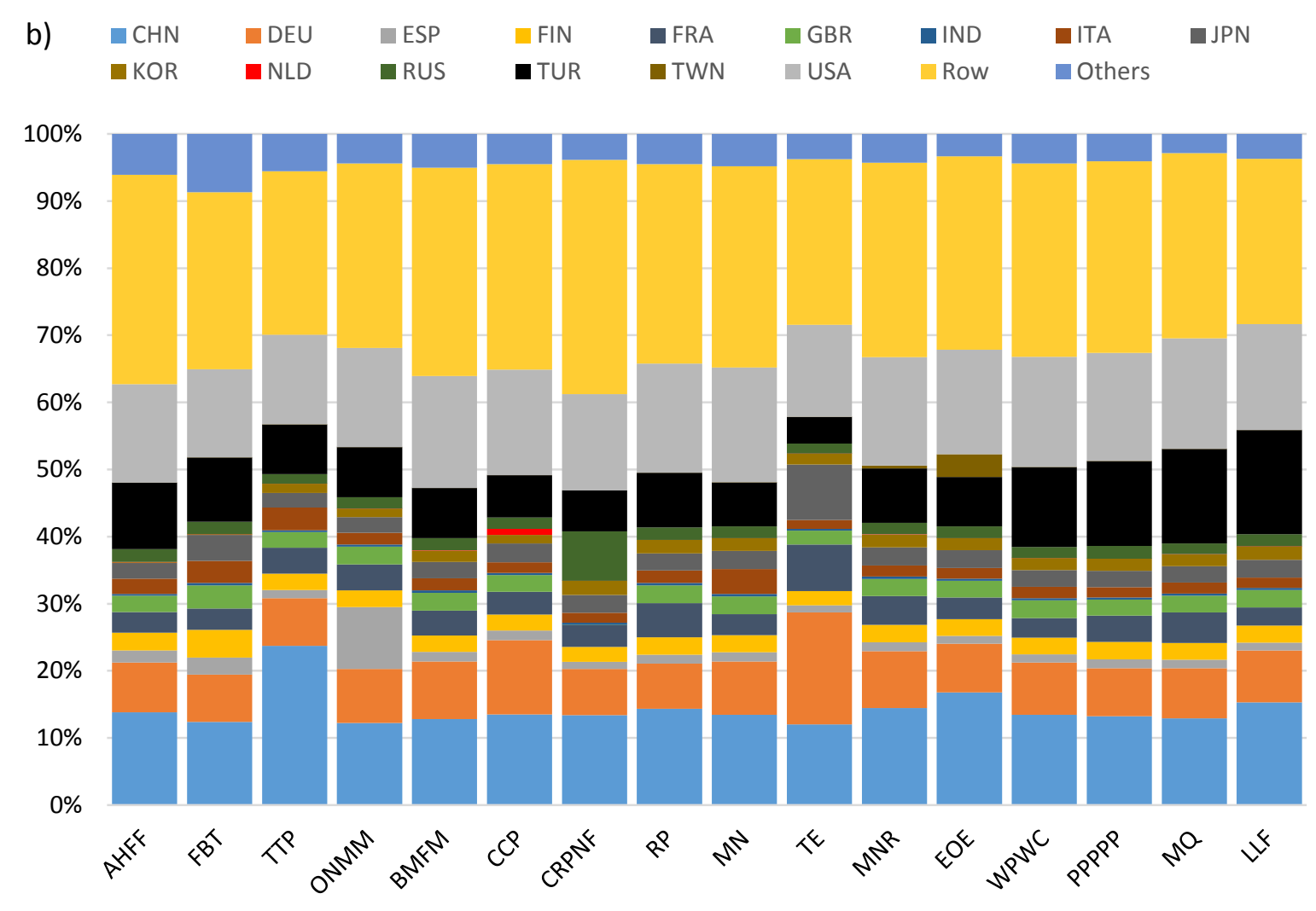

Fig 5. A global carbon footprint and energy use distribution of 16 Turkish manufacturing sectors as an average of impacts between 2000 and 2009 (a: carbon footprint, b: energy use)

Finally, Fig 6 presents the global distribution of energy and carbon impacts of manufacturing sectors for the period between 2000 and 2009. This analysis is important to see the variation of global distribution of energy and carbon effects of each manufacturing sector. The results indicated that CHN, RUS, TUR and RoW had the greatest shares of carbon emissions over the 9-year period. The shares of CHN and RUS showed a declining trend from 2000 to 2009. On the other hand, TUR's share started to increase in 2007. Overall, the largest portion of total carbon emissions was found in TUR's regional boundary, which ranged between $40 \%$ and $60 \%$ of total carbon emissions. For instance, in 2009 , TUR was found to be responsible for around $60 \%$ of total carbon emissions and the rest was distributed to other world countries (see Fig 6a).

Fig $6 \mathrm{~b}$ also showed the contribution of trading countries to total energy use of Turkish manufacturing. Among the nations, CHN, DEU, FRA, TUR, USA and RoW had the biggest share of energy production to support Turkish manufacturing sectors. As an important finding, the share of CHN showed a steady increase between 2000 and 2009. In 2009, China, United States, and Rest-of-the-World's contributions, as a whole, were found to be more than $50 \%$ of total energy use of Turkish manufacturing. The CHN's contribution in 2009 was found to be more than $10 \%$ of total energy use while over $20 \%$ of total energy was attributed to production activities of other countries grouped under RoW. Starting from 2001, USA has shown a declining trend for its contribution to total energy use. TUR's energy share varied between $9 \%$ and $23 \%$ of total impacts, and had its highest value in 2008 , and 2009. The countries such as ESP, FIN, FRA, GBR, ITA, JPN, KOR and RUS had the least portion among the global trading partners of TUR, and their share in total energy footprint of Turkish manufacturing did not show a considerable fluctuations over the 10 -years period. 

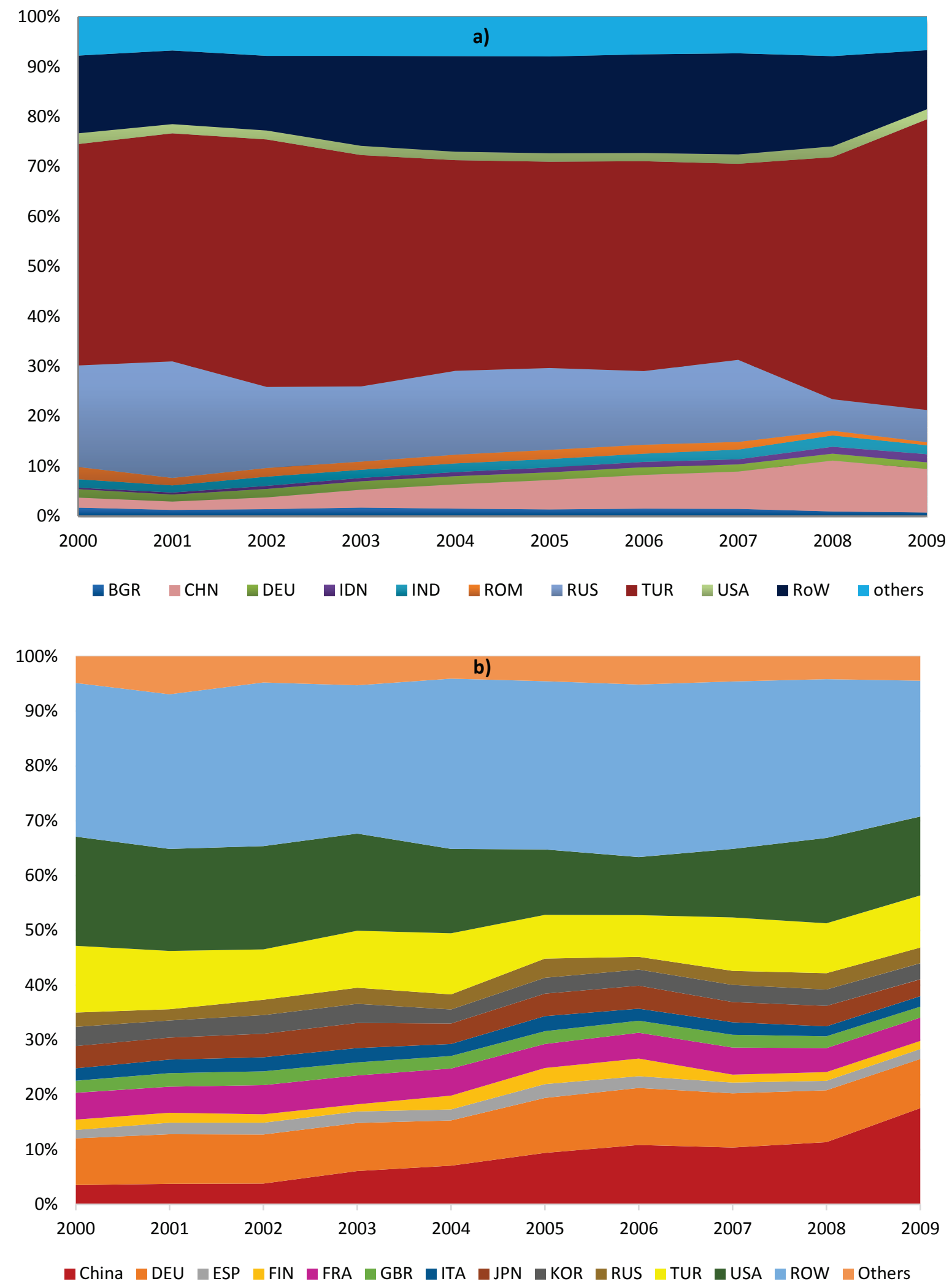

Fig 6. Carbon footprint and energy use trend of Turkish manufacturing sectors between 2000 and 2009 (a: carbon footprint, b: energy use)

\section{Discussion and Conclusions}

This study addresses the energy-climate-manufacturing nexus for the Turkish manufacturing industries and showed the importance of consumption-based approaches with the inclusion of global manufacturing supply 
chains. Furthermore, it provides crucial insights for policy makers, industry stakeholders, and the scientific community and can pave the way for further development in manufacturing sustainability assessment research. For practical applications, the proposed decision-support framework should include further collaborations with industry stakeholders. Since the major hotspots in global supply chains were revealed, policy makers can identify the major stakeholders in each sector and can investigate the root causes. The major insights and conclusions are presented as follows:

\subsection{One size does not fit all: The need for sector-specific strategies}

The global trade-linked carbon emissions and energy consumption of the manufacturing sectors highlighted the need for sector-specific strategies to mitigate GHG emissions and shift to a more energy-efficient economy. Consequently, strategies should be developed based on the supply chain characteristics reflecting the contribution of onsite, upstream and $\mathrm{T}+\mathrm{W}+\mathrm{R}$ segments, and energy and carbon footprint reduction potential of each sector. While carbon and energy intensity of some sectors were attributed to supply chain, for other sectors such as ONMM, WPWC, TTP, FBT and AHFF, reducing onsite impacts should be prioritized. The percentage contribution of upstream suppliers to the total carbon emissions is found to be much higher ( $80 \%$ or higher) for majority of the sectors (about 75\% of the sectors), whereas onsite emissions of sectors such as WPWC, ONMM, and AHFF have much greater shares. On the other hand, upstream energy consumption of these sectors is greater than their onsite emissions. Hence, the policies aiming to increase energy efficiency may not necessarily reduce the GHG emissions effectively. While AHFF sector had the highest carbon emissions based on their total output, the total energy use of AHFF was not the highest. Although there might be strong correlation between energy and carbon footprints, different trends can also be observed in such sectors. Another example is the ONMM sector: The results showed that ONMM is the most carbon-intensive sector in the terms of emissions per \$M of output and it is the fourth largest contributor in the terms of its relative size. However, ONMM sector was not found to be among the top-5 sectors based on its total and per \$M output energy consumption. Similarly, WPWC was responsible for the least amount of energy in comparison with other sectors; whereas it was found to be as one of the top contributors of carbon emissions per \$M basis.

\subsection{Carbon and energy hotspots: Insights for Turkish manufacturing sectors and supply chains}

Revealing the most carbon and energy intensive supply chain components is crucial to be able to identify the root causes and detect the right domains to focus on. Results indicate that the total carbon and energy impacts of sectors are largely attributed to upstream suppliers and onsite activities; whereas $\mathrm{T}+\mathrm{W}+\mathrm{R}$ have relatively much smaller impact. Among the upstream suppliers, Electricity, Gas and Water Supply (EGWS) was found to be most dominant supply chain component of the top carbon intensive sectors. Although this is an expected finding, it highlights the fossil fuel dependence of electric power generation. Hence, use of renewable energy for electricity production is vital to mitigate carbon emissions and stabilize the global warming threat in the long run. Furthermore, any improvement in EGWS sector can result in credible footprint reductions compared to other supply chain components since it is a major component of the supply chain of manufacturing sectors and the largest contributor to carbon emissions. On the other hand, major supply chain contributors to the energy consumption of manufacturing sectors have a different structure. The Coke, Refined Petroleum and Nuclear Fuel sector was found to be the main driver of energy use in upstream supply chains. Similarly, energy efficiency improvement for this sector will increase performance of other sectors significantly. Furthermore, CRPNF was the most energy intensive sector and supply chain energy consumption account for about $70 \%$ of the sector's total. 
The most influential component of its supply chain is the MQ sector whose energy consumption trend is expected to increase due to expanding coal mining in Turkey in recent years.

\subsection{Revealing the big picture: Broadening the current understanding of supply chain sustainability}

Globalization of the world economy fastens the separation between the consumption and production spatially. While resource extraction and agricultural production take place in some parts of the word, industrial manufacturing, redistribution, and consumption occur in different parts of the world (Wiedmann et al. 2011). Hence, to be able to analyze supply chain sustainability and promote sustainable consumption and production policies, international supply chains need to be considered as part of life cycle assessment methodologies (Chaabane et al. 2012). On the other hand, current sustainable supply chain management understanding prioritizes the social, environmental, and economic goals of an individual company or a country, region,etc. for improving long-term economic performance of the focused system and its supply chains (Carter and Rogers, 2008). While it is appropriate from an individual company's perspective, when the entire supply chain network and its integration with environmental sustainability are considered, a broader understanding is necessary. In the literature, most of the studies addressing issues related to supply chain sustainability assessment lack holistic international tradelinked scope, and focus on a specific phase of supply chain such as transportation and logistics (Cholette and Venkat, 2009; Egilmez and Park, 2014; Elhedhli and Merrick, 2012; Halldórsson and Kovács, 2010; Soysal et al. 2012) and inventory management (Bouchery et al. 2012; Hua et al. 2011). Although analyzing different segment of supply chains are necessary and can be beneficial for corporate level supply chain management efforts (Benjaafar et al. 2013), the results of this research showed that these segments have very small impact compared to onsite and upstream impacts. Hence, mapping the energy and carbon hotspots for each sector throughout global supply chain can guide policy makers, industry stakeholders, and researchers to canalize the efforts to the right domains.

\subsection{Lack of Communication in a Globalized World}

In a globalized world, which is woven by highly complex web of global supply chains, sustainability of any region depends on the sustainability of many other regions (Kissinger and Rees, 2010). Considering that individual companies does not have control over their higher order upstream suppliers; top-down approaches and communication among international authorities, organizations, policy makers are essential actions need to be taken in order to address issues related to climate change as well as energy efficiency, and trigger transformation of long talks into actions. Lack of communication about the risks of climate change is a major problem preventing science contributing the decision making processes and playing appropriate role in policies addressing issues related to Climate (Moser, 2010; Sterman, 2011). Mental models of individuals and prejudices prevent the communications and result in biases (Sterman \& Sweeney, 2007). A long term commitment and strategy is needed to coordinate and improve the effectiveness of policies.

\section{Recommendations \& Future Remarks}

This paper is an important step toward integrating a global MRIO perspective into macro level energy and climate effects of manufacturing supply chains. While the majority of researchers have been focusing on particular parts of the manufacturing activities from product or process perspectives with a limited focus on regional impacts and supply chain phases, sustainability assessment research often lacks a systems-level approach. In this context, current research methodology will be a robust framework since it provides a comprehensive sustainability 
assessment that addresses the supply chains and global impacts as an "umbrella" type of research methodology. For future research, the authors also propose the important extensions of current sustainable supply chain research for manufacturing activities as 'using high sector and country resolution global MRIO frameworks', 'considering the social and economic aspects of manufacturing in addition to the environment' and finally 'considering the dynamics relationships between the indicators of sustainability and their ripple effects on the long-term sustainability of manufacturing'.

\subsection{High-resolution sectors, more detailed regions, improved data availability, quality, and accuracy}

In this paper, the researchers used the WIOD which has become very popular and is widely cited global MRIO database (Arto and Dietzenbacher, 2014). Although the proposed methodology is robust and sound as it is capable of capturing global trade-links through time, there is need for certain improvements to develop more effective and accurate framework. First, the level of aggregation is critical point that needs to be addressed in future. The findings of recent studies also showed that disaggregation of $\mathrm{I}-\mathrm{O}$ data are superior to aggregating environmental data in determining I-O multipliers and minimize uncertainties in LCI results (Lenzen, 2011; Steen-Olsen et al. 2014). Second, the comprehensive review on I-O studies strongly emphasized that sustainability implications of manufacturing sectors must be analyzed with a set of environmental metrics as extensive as possible, covering the globe and discerning as many as possible sectors and countries, including long-time series (Hoekstra, 2010; Tukker and Dietzenbacher, 2013). Therefore, the authors aim to expand the methodology of current analysis with high country and sector resolution MRIO data and even more intra-country regional detail. This level of disaggregation will be so critical for analysis of industrial sectors with upstream supply chain dominance. For instance, the EXIOPOL covers the 27 EU member states as well as 16 non-EU countries with RoW accounts (Tukker et al. 2009). This global MRIO database aims to have a detailed view of economic sectors discerning 129 sectors. This global MRIO database used more detailed sector and product accounts to split up product and industry totals; however current version is limited to 2000 data which does not enable us to conduct a time series analysis. Furthermore, it should be noted that global MRIO modes are subject to uncertainties due to sectoral aggregation and gathering the environmental accounts data (Lenzen et al. 2010). Also, combining regional models with MRIO analysis can be a sound methodology in order to consider the role of regional variations (Liang et al, 2007; Okedera et al. 2006).

\subsection{The Balancing Act: Towards triple bottom line sustainability assessment of manufacturing sectors}

Although the primary goal of supply chain management is considered as supply chain surplus through minimizing total supply chain cost and maximizing profits, this understanding has to be shifted to a broader concept that aims to find balance between the economic, social and ecological consequences of supply chain operations. To be able to manage the technological advancements towards realizing the goals of sustainable development, it is crucial to evaluate the TBL sustainability impacts of industrial activities in order to achieve economically viable, environmentally benign and socially acceptable policies towards realizing the objectives of sustainable development (Elkington, 1997). In the literature, several studies emphasized the importance of the three pillars of sustainability in supply chain management research (Clift, 2004; Seuring and Muller, 2008; Seuring et al. 2008). However, only a handful of studies have focused on integrating all dimensions of sustainability into sustainable supply chain management research (Foran et al. 2005; Wiedmann and Lenzen, 2009; Onat et al. 2014a). Furthermore, globalization is an important factor for shaping the global supply chain networks of production activities and associated TBL impacts. There are important efforts towards presenting the critical TBL measures 
for domestic economies and their global effects. In near future, a global MRIO analysis can be primary policy making framework for world economies in order to trace the TBL sustainability performance of their production supply chains at regional and global scale (Balancing the G20’s Global Impact, 2014).

\subsection{Revealing the causal relationship and the system behavior}

Effective decision-making requires a system thinking approach and an understanding of the behavior of the growing dynamic complexity of the globally linked manufacturing sectors (Egilmez and Tatari, 2012; Onat et al. 2014c; Sterman, 2000, Onat et al. 2016b). The global warming, energy consumption and economic output of manufacturing sectors are interconnected with feedback relationships, ripple and side effects. While MRIO models are very significant, they are not capable of capturing the causal relationships among the manufacturing sectors and environmental impacts. System dynamics modeling serves best to reveal these relationships since it helps to quantitatively define the feedback mechanisms, potential delays, and multi-dimensional causal relationships of a particular system (Davies, 2008; Sterman, 2012). With the integration of system dynamics modeling, the nexus between the energy use and global climate change and the system's behavior over time can be identified and more effective policies can be developed.

\section{References}

Ahi, P., \& Searcy, C., 2013. A comparative literature analysis of definitions for green and sustainable supply chain management. Journal of Cleaner Production, 52, 329-341.

Andrew, R. M., \& Peters, G. P., 2013. A multi-region input-output table based on the global trade analysis project database (GTAP-MRIO). Economic Systems Research, 25(1), 99-121.

Andrew, R., Peters, G. P., \& Lennox, J., 2009. Approximation and regional aggregation in multi-regional inputoutput analysis for national carbon footprint accounting. Economic Systems Research, 21(3), 311-335.

Arto, I., Andreoni, V., \& Rueda Cantuche, J. M., 2015. Global Impacts of the Automotive Supply Chain Disruption Following the Japanese Earthquake of 2011. Economic Systems Research, 27(3), 306-323.

Arto, I., Rueda-Cantuche, J. M., \& Peters, G. P., 2014a. Comparing the GTAP-MRIO and WIOD databases for carbon footprint analysis. Economic Systems Research, 26(3), 327-353.

Arto, I., Rueda-Cantuche, J. M., Andreoni, V., Mongelli, I., \& Genty, A., 2014b. The game of trading jobs for emissions. Energy policy, 66, 517-525.

Arto, I., \& Dietzenbacher, E., 2014. Drivers of the growth in global greenhouse gas emissions. Environmental science \& technology. 48 (10), 5388-5394.

Ayvaz, B., Bolat, B., \& Aydın, N., 2015. Stochastic reverse logistics network design for waste of electrical and electronic equipment. Resources, Conservation and Recycling, 104, 391-404.

Balancing the G20's Global Impacts, 2014. Available

at: http://www.csu.edu.au/research/ilws/publications/technical-reports/g20s-global-impact

Benjaafar, S., Li, Y., \& Daskin, M., 2013. Carbon Footprint and the Management of Supply Chains: Insights From Simple Models. IEEE Transactions on Automation Science and Engineering, 10(1), 99-116.

Bortolamedi, M. (2015). Accounting for hidden energy dependency: The impact of energy embodied in traded goods on cross-country energy security assessments. Energy, 93, 1361-1372. 
Bouchery, Y., Ghaffari, A., Jemai, Z., \& Dallery, Y., 2012. Including sustainability criteria into inventory models. European Journal of Operational Research, 222(2), 229-240.

Bush, R., Jacques, D. A., Scott, K., \& Barrett, J., 2014. The carbon payback of micro-generation: An integrated hybrid input-output approach. Applied Energy, 119, 85-98.

Chaabane, A., Ramudhin, A., \& Paquet, M., 2012. Design of sustainable supply chains under the emission trading scheme. International Journal of Production Economics, 135(1), 37-49.

Chen, S., \& Chen, B., 2015. Urban energy consumption: Different insights from energy flow analysis, inputoutput analysis and ecological network analysis. Applied Energy, 138, 99-107.

Cholette, S., \& Venkat, K., 2009. The energy and carbon intensity of wine distribution: A study of logistical options for delivering wine to consumers. Journal of Cleaner Production, 17(16), 1401-1413.

Clift, R., 2004. Metrics for supply chain sustainability. In Technological Choices for Sustainability (pp. 239-253). Springer Berlin Heidelberg.

Davies, E. G. R., 2008. An Integrated System Dynamics Model for Analyzing Behaviour of the Social-EconomicClimatic System: Model Description and Model Use Guide.

Dietzenbacher, E., Lenzen, M., Los, B., Guan, D., Lahr, M. L., Sancho, F.,... \& Yang, C., 2014. Input-output analysis: the next 25 years. Economic Systems Research, 25(4), 369-389.

Dietzenbacher, E., Los, B., Stehrer, R., Timmer, M., \& de Vries, G., 2013. The construction of world input-output tables in the WIOD project. Economic Systems Research, 25(1), 71-98.

Egilmez, G., \& Tatari, O., 2012. A dynamic modeling approach to highway sustainability: Strategies to reduce overall impact. Transportation Research Part A: Policy and Practice, 46(7), 1086-1096.

Egilmez, G., Kucukvar, M., Tatari, O., \& Bhutta, M. K. S., 2014. Supply chain sustainability assessment of the U.S. food manufacturing sectors: A life cycle-based frontier approach. Resources, Conservation and Recycling, 82, 8-20.

Egilmez, G., \& Park, Y. S., 2014. Transportation related carbon, energy and water footprint analysis of U.S. manufacturing: An eco-efficiency assessment. Transportation Research Part D: Transport and Environment, 32, 143-159.

Egilmez, G., Kucukvar, M., \& Tatari, O., 2013. Sustainability assessment of U.S. manufacturing sectors: an economic input output-based frontier approach. Journal of Cleaner Production, 53, 91-102.

Elhedhli, S., \& Merrick, R., 2012. Green supply chain network design to reduce carbon emissions. Transportation Research Part D: Transport and Environment.

Elkington, J., 1997. Cannibals with forks. The triple bottom line of 21 st century.

European Commission, 2003. The Future of Manufacturing in Europe 2015-2020: The Challenge for Sustainability.

European Commission, 2010. New Public-Private Partnerships for Research in Manufacturing, Construction, and Automotive Sectors.

European Commission, 2011. Key Figures: Market Observatory for Energy.

European Commission, 2013. European Economy: Member States’ Energy Dependence-An Indicator-Based Assessment. 
European Commission, 2014. The 2020 climate and energy package. Available at: http://ec.europa.eu/clima/policies/package/index_en.htm

European Environment Agency., 2013. Environmental Pressures from European Consumption and Production.

EuroStat, 2008. Statistical classification of economic activities in the European Community. Luxembourg.

Ewing, B. R., Hawkins, T. R., Wiedmann, T. O., Galli, A., Ertug Ercin, A., Weinzettel, J., \& Steen-Olsen, K., 2012. Integrating ecological and water footprint accounting in a multi-regional input-output framework. Ecological Indicators, 23, 1-8.

Feng, K., Chapagain, A., Suh, S., Pfister, S., \& Hubacek, K. (2011). Comparison of bottom-up and top-down approaches to calculating the water footprints of nations. Economic Systems Research, 23(4), 371-385.

Foran, B., Lenzen, M., Dey, C., \& Bilek, M., 2005. Integrating sustainable chain management with triple bottom line accounting. Ecological economics, 52(2), 143-157.

Galli, A., Weinzettel, J., Cranston, G., \& Ercin, E., 2013. A Footprint Family extended MRIO model to support Europe's transition to a One Planet Economy. Science of the total environment, 461, 813-818.

Genty, A., Arto, I., \& Neuwahl, F., 2012. Final database of environmental satellite accounts: technical report on their compilation. WIOD Documentation. Available from: http://www. wiod.org/publications/source_docs/Environmental_Sources.pdf.

Halldórsson, Á., \& Kovács, G., 2010. The sustainable agenda and energy efficiency: Logistics solutions and supply chains in times of climate change. International Journal of Physical Distribution \& Logistics Management, 40(1/2), 5-13.

Helm, D., 2014. The European framework for energy and climate policies. Energy Policy, 64, 29-35.

Hertwich, E. G., \& Peters, G. P., 2009. Carbon footprint of nations: A global, trade-linked analysis. Environmental science \& technology, 43(16), 6414-6420.

Hoekstra, R., 2010. Towards a Complete Overview of Peer-Reviewed Articles on Environmentally Input-Output analysis (Paper presented at the 18th International Input-Output Conference, Sydney, Australia).

Hua, G., Cheng, T. C. E., \& Wang, S., 2011. Managing carbon footprints in inventory management. International Journal of Production Economics, 132(2), 178-185.

International Energy Agency (IEA), 2013. World Energy Outlook: Energy Special Report. Available at: http://www.worldenergyoutlook.org/publications/weo-2013/

Kissinger, M., \& Rees, W. E., 2010. An interregional ecological approach for modelling sustainability in a globalizing world-Reviewing existing approaches and emerging directions. Ecological Modelling, 221(21), $2615-2623$.

Kucukvar, M., Egilmez, G., Onat, N. C., \& Samadi, H., 2015. A global, scope-based carbon footprint modeling for effective carbon reduction policies: Lessons from the Turkish manufacturing. Sustainable Production and Consumption, 1, 47-66.

Kucukvar, M., \& Samadi, H., 2015. Linking national food production to global supply chain impacts for the energy-climate challenge: the cases of the EU-27 and Turkey. Journal of Cleaner Production, 108, 395-408.

Kucukvar, M., Egilmez, G., \& Tatari, O., 2014. Sustainability assessment of U.S. final consumption and investments: triple-bottom-line input-output analysis. Journal of Cleaner Production, 81, 234-243.

Kucukvar, M., \& Tatari, O., 2013. Towards a triple bottom-line sustainability assessment of the U.S construction industry. The International Journal of Life Cycle Assessment, 18(5), 958-972. 
Lan, J., Malik, A., Lenzen, M., McBain, D., \& Kanemoto, K., 2016. A structural decomposition analysis of global energy footprints. Applied Energy, 163, 436-451.

Larsen, H. N., \& Hertwich, E. G., 2010. Implementing Carbon Footprint Based Calculation Tools in Municipal Greenhouse Gas Inventories. Journal of Industrial Ecology, 14(6), 965-977.

Lenzen, M., Moran, D., Kanemoto, K., \& Geschke, A., 2013. Building Eora: a global multi-region input-output database at high country and sector resolution. Economic Systems Research, 25(1), 20-49.

Lenzen, M., 2011. Aggregation versus disaggregation in input-output analysis of the environment. Economic Systems Research, 23(1), 73-89.

Lenzen, M., Wood, R., \& Wiedmann, T., 2010. Uncertainty analysis for multi-region input-output models-a case study of the UK's carbon footprint. Economic Systems Research, 22(1), 43-63.

Lenzen, M., Wood, R., \& Wiedmann, T., 2010. Uncertainty analysis for multi-region input-output models-a case study of the UK's carbon footprint. Economic Systems Research, 22(1), 43-63.

Lenzen, M., 2000. Errors in Conventional and Input-Output-based Life-Cycle Inventories. Journal of Industrial Ecology, 4(4), 127-148.

Leontief, W., 1970. Environmental repercussions and the economic structure: an input-output approach. The review of economics and statistics, 262-271.

Li, X., Feng, K., Siu, Y. L., \& Hubacek, K., 2012. Energy-water nexus of wind power in China: The balancing act between $\mathrm{CO}_{2}$ emissions and water consumption. Energy policy, 45, 440-448.

Liang, Q. M., Fan, Y., \& Wei, Y. M., 2007. Multi-regional input-output model for regional energy requirements and $\mathrm{CO}_{2}$ emissions in China. Energy Policy, 35(3), 1685-1700.

Lin, J., Liu, Y., Meng, F., Cui, S., \& Xu, L., 2013. Using hybrid method to evaluate carbon footprint of Xiamen City, China. Energy Policy, 58, 220-227.

Liu, Z., Geng, Y., Lindner, S., Zhao, H., Fujita, T., Guan, D., 2012. Embodied energy use in China's industrial sectors. Energy policy, 49, 751-758.

MATLAB., 2012. Version 7.14.0. Natick. The Math Works Inc, Massachusetts.

Matthews, H. S., Hendrickson, C. T., \& Weber, C. L., 2008. The importance of carbon footprint estimation boundaries. Environmental science \& technology, 42(16), 5839-5842.

Miller, R. E., \& Blair, P. D., 2009. Input-output analysis: foundations and extensions. Cambridge University Press.

Minx, J. C., Wiedmann, T., Wood, R., Peters, G. P., Lenzen, M., Owen, A., ... \& Ackerman, F., 2009. Inputoutput analysis and carbon footprinting: an overview of applications. Economic Systems Research, 21(3), 187216.

Moran, D., \& Wood, R., 2014. Convergence between the EORA, WIOD, EXIOBASE, and OPENEU'S consumption-based carbon accounts. Economic Systems Research, 26(3), 245-261.

Moser, S. C., 2010. Communicating climate change: history, challenges, process and future directions. Wiley Interdisciplinary Reviews: Climate Change, 1(1), 31-53.

Mundaca, L., Román, R., \& Cansino, J. M., 2015. Towards a green energy economy? A macroeconomic-climate evaluation of Sweden's CO2 emissions. Applied Energy, 148, 196-209.

Oita, A., Malik, A., Kanemoto, K., Geschke, A., Nishijima, S., \& Lenzen, M., 2016. Substantial nitrogen pollution embedded in international trade. Nature Geoscience (in press). 
Okadera, T., Watanabe, M., \& Xu, K., 2006. Analysis of water demand and water pollutant discharge using a regional input-output table: an application to the City of Chongqing, upstream of the Three Gorges Dam in China. Ecological Economics, 58(2), 221-237.

Onat, N. C., Kucukvar, M., Tatari, O., \& Zheng, Q. P., 2016a. Combined application of multi-criteria optimization and life-cycle sustainability assessment for optimal distribution of alternative passenger cars in US. Journal of Cleaner Production, 112, 291-307.

Onat, N. C., Kucukvar, M., Tatari, O., Egilmez, G. 2016b. Integration of System Dynamics Approach towards Deeping and Broadening the Life Cycle Sustainability Assessment Framework: A Case for Electric Vehicles. International Journal of Life Cycle Assessment (in press).

Onat, N. C., Gumus, S., Kucukvar, M., \& Tatari, O., 2015a. Application of the TOPSIS and intuitionistic fuzzy set approaches for ranking the life cycle sustainability performance of alternative vehicle technologies. Sustainable Production and Consumption, 6, 12-25.

Onat, N. C., Kucukvar, M., \& Tatari, O., 2015b. Conventional, hybrid, plug-in hybrid or electric vehicles? Statebased comparative carbon and energy footprint analysis in the United States. Applied Energy, 150, 36-49.

Onat, N. C., Kucukvar, M., \& Tatari, O., 2014a. Integrating triple bottom line input-output analysis into life cycle sustainability assessment framework: the case for U.S. buildings. The International Journal of Life Cycle Assessment, 1-18.

Onat, N. C., Kucukvar, M., \& Tatari, O., 2014b. Scope-based carbon footprint analysis of U.S. residential and commercial buildings: an input-output hybrid life cycle assessment approach. Building and Environment, 72, 5362.

Onat, N. C., Egilmez, G., \& Tatari, O., 2014c. Towards greening the U.S. residential building stock: A system dynamics approach. Building and Environment, 78, 68-80.

Park, Y. S., Egilmez, G., \& Kucukvar, M., 2016. Emergy and end-point impact assessment of agricultural and food production in the United States: A supply chain-linked Ecologically-based Life Cycle Assessment. Ecological Indicators, 62, 117-137.

Park, Y. S., Egilmez, G., \& Kucukvar, M., 2015. A Novel Life Cycle-based Principal Component Analysis Framework for Eco-efficiency Analysis: Case of the United States Manufacturing and Transportation Nexus. Journal of Cleaner Production, 92, 327-342.

Peters, G. P., Andrew, R., \& Lennox, J., 2011. Constructing an environmentally-extended multi-regional inputoutput table using the GTAP database. Economic Systems Research, 23(2), 131-152.

Peters, G. P., \& Hertwich, E. G., 2009. The application of multi-regional input-output analysis to industrial ecology. In Handbook of input-output economics in industrial ecology (pp. 847-863). Springer Netherlands.

Rueda-Cantuche, J. M., Beutel, J., Neuwahl, F., Mongelli, I., \& Loeschel, A., 2009. A symmetric input-output table for EU27: latest progress. Economic Systems Research, 21(1), 59-79.

Sarkis, J., Zhu, Q., \& Lai, K. H., 2011. An organizational theoretic review of green supply chain management literature. International Journal of Production Economics, 130(1), 1-15.

Seuring, S., 2013. A review of modeling approaches for sustainable supply chain management. Decision Support Systems, 54(4), 1513-1520.

Seuring, S., \& Müller, M., 2008. From a literature review to a conceptual framework for sustainable supply chain management. Journal of cleaner production, 16(15), 1699-1710.

Seuring, S., Sarkis, J., Müller, M., \& Rao, P., 2008. Sustainability and supply chain management-an introduction to the special issue. Journal of Cleaner Production, 16(15), 1545-1551.

Song, J., Yang, W., Higano, Y., \& Wang, X. E., 2015. Dynamic integrated assessment of bioenergy technologies for energy production utilizing agricultural residues: An input-output approach. Applied Energy, 158, 178-189. 
Soysal, M., Bloemhof-Ruwaard, J. M., \& van der Vorst, J. G. A. J., 2014. Modelling food logistics networks with emission considerations: The case of an international beef supply chain. International Journal of Production Economics, 152, 57-70.

Soysal, M., Bloemhof-Ruwaard, J. M., Meuwissen, M. P., \& van der Vorst, J. G., 2012. A review on quantitative models for sustainable food logistics management. International Journal on Food System Dynamics, 3(2), 136155 .

SPSS software Predictive analytics software and solutions., 2013. http://www 01.ibm.com/software/analytics/spss/.

Steen-Olsen, K., Owen, A., Hertwich, E. G., \& Lenzen, M., 2014. Effects of Sector Aggregation on $\mathrm{CO}_{2}$ Multipliers in Multiregional Input-Output Analyses. Economic Systems Research, 26(3), 284-302.

Sterman, J. D., 2012. Sustainability Science. (M. P. Weinstein \& R. E. Turner, Eds.). New York, NY: Springer New York.

Sterman, J. D., 2011. Communicating climate change risks in a skeptical world. Climatic Change, 108(4), 811826.

Sterman, J. D., \& Sweeney, L. B., 2007. Understanding public complacency about climate change: adults' mental models of climate change violate conservation of matter. Climatic Change, 80(3-4), 213-238.

Sterman, J. D., 2000. Business Dynamics: System Thinking and Modeling for a Complex World. Boston.

Su, B., \& Ang, B. W., 2014. Input-output analysis of $\mathrm{CO}_{2}$ emissions embodied in trade: a multi-region model for China. Applied Energy, 114, 377-384.

Suh, S., Lenzen, M., Treloar, G. J., Hondo, H., Horvath, A., Huppes, G., ... \& Norris, G., 2004. System boundary selection in life-cycle inventories using hybrid approaches. Environmental Science \& Technology, 38(3), 657664.

Timmer, M.P., 2012. The World Input-Output Database (WIOD): Contents, Sources and Methods. WIOD Working Paper Number 10, downloadable at http://www.wiod.org/publications/papers/wiod10.pdf

Tukker, A., \& Dietzenbacher, E., 2013. Global multiregional input-output frameworks: an introduction and outlook. Economic Systems Research, 25(1), 1-19.

Tukker, A., Poliakov, E., Heijungs, R., Hawkins, T., Neuwahl, F., Rueda-Cantuche, J. M.,... \& Bouwmeester, M., 2009. Towards a global multi-regional environmentally extended input-output database. Ecological Economics, 68(7), 1928-1937.

Turkish Ministry of Environment and Urban Planning., 2014. Monitoring and Reporting of Greenhouse Gas Emissions. Available at: http://www.resmigazete.gov.tr/eskiler/2014/07/20140722-5.htm.

Turkish Ministry of Energy and Natural Resources., 2013. Energy Efficiency Strategy Paper. Available at: http://www.eie.gov.tr/verimlilik/document/Energy_Efficiency_Strategy_Paper.pdf

U.S. EPA., 2013. Inventory of U.S. Greenhouse Gas Emissions and Sinks: 1990-2011; Office of Global Warming: Washington, DC.

WBCSD, 2013. Water, Energy and Climate Change: A contribution from the business community. Available at: http://www.wbcsd.org/Pages/EDocument/EDocumentDetails.aspx?ID=40

Weber, C. L., \& Matthews, H. S., 2008. Quantifying the global and distributional aspects of American household carbon footprint. Ecological Economics, 66(2), 379-391. 
Wiedmann, T. O., Chen, G., \& Barrett, J., 2015. The Concept of City Carbon Maps: A Case Study of Melbourne, Australia. Journal of Industrial Ecology (in press).

Wiedmann, T., Barrett, J., 2013. Policy-relevant applications of environmentally extended MRIO databasesExperiences from the UK. Economic Systems Research, 25(1), 143-156.

Wiedmann, T., Wilting, H. C., Lenzen, M., Lutter, S., \& Palm, V., 2011. Quo Vadis MRIO? Methodological, data and institutional requirements for multi-region input-output analysis. Ecological Economics, 70(11), 1937-1945.

Wiedmann, T., Wood, R., Minx, J. C., Lenzen, M., Guan, D., \& Harris, R., 2010. A carbon footprint time series of the UK-results from a multi-region input-output model. Economic Systems Research, 22(1), 19-42.

Wiedmann, T., 2009. A review of recent multi-region input-output models used for consumption-based emission and resource accounting. Ecological Economics, 69(2), 211-222.

Wiedmann, T., \& Lenzen, M., 2009. Unravelling the impacts of supply chains-a new triple-bottom-line accounting approach and software tool. In Environmental management accounting for cleaner production (pp. 6590). Springer Netherlands.

Wiedmann, T., \& Minx, J., 2008. A definition of 'carbon footprint'. Ecological economics research trends, 1, 111.

Yu, Y., Feng, K., Hubacek, K., \& Sun, L., 2016. Global Implications of China's Future Food Consumption. Journal of Industrial Ecology (in press).

Yu, Y., Hubacek, K., Feng, K., \& Guan, D., 2010. Assessing regional and global water footprints for the UK. Ecological Economics, 69(5), 1140-1147.

Zhang, B., Qiao, H., Chen, Z. M., \& Chen, B., 2015. Growth in embodied energy transfers via China's domestic trade: Evidence from multi-regional input-output analysis. Applied Energy (in press).

Zhang, H., \& Lahr, M. L., 2014. China's energy consumption change from 1987 to 2007: A multi-regional structural decomposition analysis. Energy Policy, 67, 682-693.

Zhang, B., Qiao, H., \& Chen, B., 2014. Embodied energy uses by China's four municipalities: A study based on multi-regional input-output model. Ecological Modelling (in press).

Zhu, Q., Geng, Y., Fujita, T., \& Hashimoto, S., 2010. Green supply chain management in leading manufacturers: Case studies in Japanese large companies. Management Research Review, 33(4), 380-392. 